Florida International University FIU Digital Commons

\title{
Factors affecting BMI and hemoglobin levels of mothers and infants in Kuwait
}

\author{
Ahmad R. Al-Haifi \\ Florida International University
}

DOI: $10.25148 /$ etd.FI13101577

Follow this and additional works at: https://digitalcommons.fiu.edu/etd

Part of the Dietetics and Clinical Nutrition Commons

\section{Recommended Citation}

Al-Haifi, Ahmad R., "Factors affecting BMI and hemoglobin levels of mothers and infants in Kuwait" (2001). FIU Electronic Theses and Dissertations. 1339.

https://digitalcommons.fiu.edu/etd/1339 


\section{FLORIDA INTERNATIONAL UNIVERSITY}

Miami, Florida

\section{FACTORS AFFECTING BMI AND HEMOGLOBIN LEVELS \\ OF MOTHERS AND INFANTS \\ IN KUWAIT}

A thesis submitted in partial fulfillment of the

requirements for the degree of

MASTER OF SCIENCE

in

DIETETICS AND NUTRITION

by

Ahmad R. Al-Haifi

2001 
To: Dean Ronald M. Berkman

College of Health and Urban Affairs

This Thesis, written by Ahmad R. Al-Haifi, and entitled Factors Affecting BMI and Hemoglobin Levels of Mothers and Infants in Kuwait, having been approved in respect to style and intellectual content, is referred to you for judgment.

We have read this thesis and recommend that it be approved.

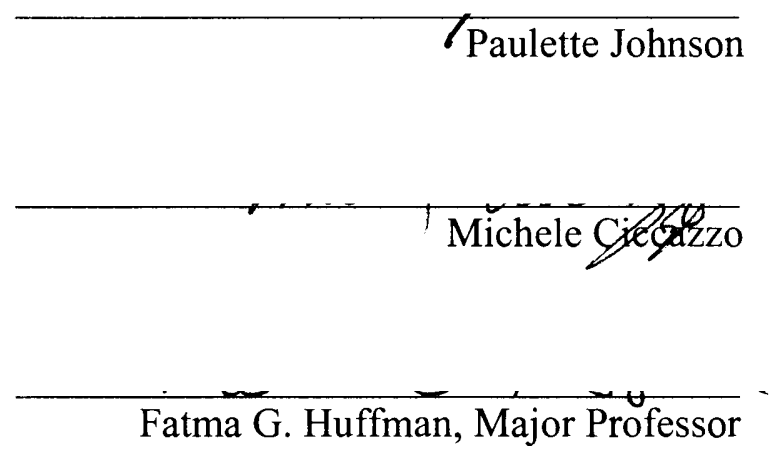

Date of Defense: June 20, 2001

The thesis of Ahmad R. Al-Haifi is approved.

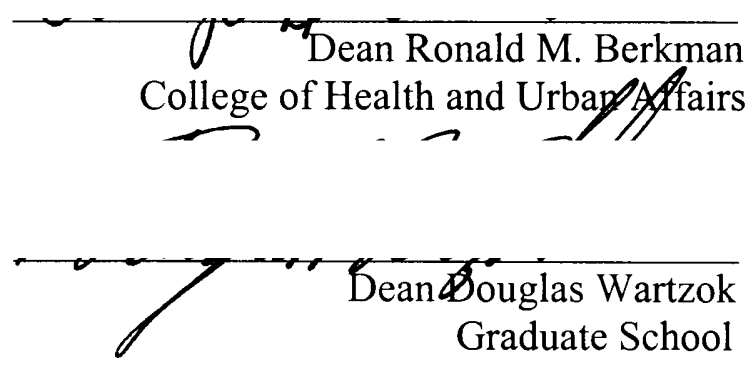

Florida International University, 2001 


\section{ACKNOWLEDGMENTS}

I wish to thank the members of my committee for their continual support and direction. In particular, I wish to thank my major professor Dr. Fatma G. Huffman for her academic and professional mentoring and her confidence in my ability to complete the task, while striving for excellence in developing a significant methodology. Moreover, Dr. Paulette Johnson is to be commended for her contribution and guidance regarding statistical analysis, an area for which I owe her much gratitude. I would like to thank Dr. Michele Ciccazzo for overseeing the progression of my thesis and offering me guidance at every step.

Furthermore, I would like to acknowledge the Department of the Food and Nutrition Administration at the Ministry of Health in the State of Kuwait that granted me the permission to utilize this data for my thesis. In particular, I wish to thank Fawzia AlAwadi (manager), Dr. Nawal Al-Hamad (assistant manager), Dr. Montaha Al-Ragua, Entesar Al-Haifi, Fahima Al-Enizy, and Mrs. Parasana Parkash.

In conclusion, the high standard of the Department of the Food and Nutrition Administration has instilled in me a desire to continue with quality research that will academically enhance the discipline as well as to improve the quality of life for all people and in particular, for the Kuwaiti population. 


\title{
ABSTRACT OF THE THESIS \\ FACTORS AFFECTING BMI AND HEMOGLOBIN LEVELS \\ OF MOTHERS AND INFANTS \\ IN KUWAIT \\ by
}

\author{
Ahmad R. AL-Haifi \\ Florida International University, 2001 \\ Miami, Florida \\ Professor Fatma G. Huffman, Major Professor
}

The purpose of this study was two-fold: to evaluate the problems of obesity and anemia among Kuwaiti mothers and their infants. The sample was made up of 254 mothers and their infants who were between the ages of 2 to 23 months. They were selected from those attending the Health Centers in Kuwait.

The study measured the weight and height of mothers and their infants. The hemoglobin $(\mathrm{Hb})$ levels of mothers and their infants were determined by collecting the capillary blood. During the interviews, the mothers were asked about infant feeding practices, number of pregnancies, educational level, and occupation. Based on the National Center for Health Statistics reference, $8.3 \%$ of the infants were overweight compared to $11.3 \%$ among American infants. The prevalences of overweight and obesity among mothers were $44.9 \%$ and $37.8 \%$, respectively. Mothers who had a high number of pregnancies had a higher $\mathrm{BMI}$ than those who had fewer pregnancies $(\mathrm{P}=0.001)$. Less educated mothers had a significantly higher number of pregnancies $(\mathrm{P}<0.001)$. Non- 
working mothers had the highest number of pregnancies $(\mathrm{P}=0.013)$. Based on the World Health Organization standards, $24.8 \%$ of infants were anemic compared to $18.4 \%$ of the American infants. The younger and the lower body weight infants had higher prevalences of anemia $(\mathrm{P}=0.016$ and $\mathrm{P}<0.001$, respectively). Overall, $8.5 \%$ of mothers were anemic. Anemia was more common among housewives than those who were professionals $(\mathrm{P}=$ 0.042). Formula-fed infants had a higher body weight and $\mathrm{Hb}$ levels than the combination of breast/mixed-fed infants $(\mathrm{P}=0.0012$ and $\mathrm{P}=0.006$, respectively).

These findings demonstrated that infant feeding method does impact weight and $\mathrm{Hb}$ levels of infants. Furthermore, the number of pregnancies significantly affect the BMI of mothers, however, education and occupation did not affect the BMI of mothers significantly. Also, our findings reinforce the recommendation that breast-fed infants be given supplemental iron beginning at six months of life. 
II. REVIEW OF LITERATURE 4

Background on Kuwait................................................... 4

Prevalence of Overweight in Kuwait and Other Countries................... 5

Overweight and Infant Feeding Practices................................. 8

Other Factors Affecting Overweight.................................... 10

Prevalence of Anemia in Kuwait and Other Countries..................... 15

Anemia and Infant Feeding Practices................................... 16

Other factors affecting anemia........................................ 18

$\begin{array}{lr}\text { III. MATERIALS AND METHODS } & 20\end{array}$

The Objectives.................................................... 20

Research Questions................................................ 21

Hypotheses.................................................... 22

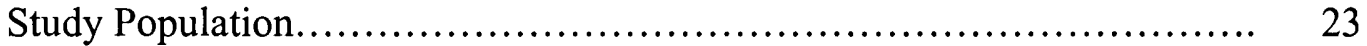

Study Setting...................................................... 23

Methodology........................................................... 23

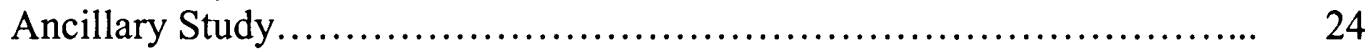

Data Analysis...................................................... 26

$\begin{array}{ll}\text { IV. RESULTS } & 27\end{array}$

Demographic Characteristics of the Participants.......................... 27

The Distribution of the Weight and Height of Kuwaiti Infants.............. 27

The Distribution of the BMI of Mothers.............................. 32

The Prevalence of Anemia among Mothers and Infants.................. 36

The Distribution of the Education and Occupation of Mothers............... 36

The Distribution of the Number of Pregnancies and the Infant

Feeding Practices......................................................... 41

Role of Mothers' Background on BMI and Hemoglobin levels.............. 41

The Effect of the Mothers' Backgrounds on their Infants' Weight and Hb Level............................................................. 45

The Effect of the Infant Feeding Practices on the Weight of the Infants..... 45

The Effect of the Infant Feeding Practices on the $\mathrm{Hb}$ Levels of the Infants

The Effect of Education and Occupation of the Mothers on their BMI and $\mathrm{Hb}$.

The Effect of the Education and Occupation on the Type of Infant

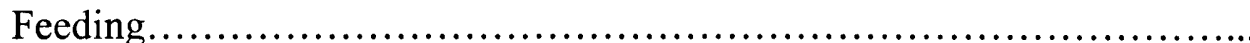


The effect of the Number of Pregnancies on the BMI and $\mathrm{Hb}$ of

Mothers............................................................. 54

V. DISCUSSION

Limitations.......................................................... 65

Summary........................................................ 65

$\begin{array}{ll}\text { LIST OF REFERENCES } & 67\end{array}$

$\begin{array}{ll}\text { APPENDICES } & 72\end{array}$ 


\section{LIST OF TABLES}

TABLE

PAGE

1. Characteristics of the Study Participants...................................... 28

2. Distribution of Infants by Age Groups.................................. 29

3. Comparisons of Age, Weight, Height, and Hemoglobin by Gender.............. 30

4. Comparisons of Age, Weight, Height, and Hemoglobin by Gender within Age Grouping........................................................ 31

5. Distribution of the Weight of Kuwaiti Infants according to the NCHS Reference... 33

6. Distribution of the Height of Kuwaiti Infants according to the NCHS Reference... 34

7. Distribution of Mothers according to their BMI............................ 35

8. Prevalence of Anemia among Mothers and Infants according to WHO Standards... 37

9. Prevalence of Anemia of Infants by Gender.................................... 38

10. Prevalence of Anemia and Differences in the Hemoglobin Levels of Infants by Age Grouping.

11. Distribution of Educational Levels of the Mothers............................. 40

12. Distribution of Occupations of the Mothers................................ 42

13. Distribution of the Number of Pregnancies of the Mothers.................... 43

14. Prevalence of the Types of Infant Feeding Practices.......................... 44

15. Relationship between the Types of Infant Feeding Practices and the Body Weight of Infants by Age Grouping..................................... 47

16. Relationship Between the Types of Infant Feeding Practices and the $\mathrm{Hb}$ Levels of Infants by Age Grouping................................ 48

17. Effect of Educational Levels of the Mothers on their BMI, Hb, and Number of Pregnancies................................................... 52 
18. Effect of Occupational Status of Mothers on their BMI, Hb, and Number of Pregnancies....................................................... 53

19. Relationship Between Infant Feeding Practices and Educational Levels of Mothers.......................................................... 55

20. Relationship Between Infant Feeding Practices and Occupational Status of Mothers............................................................ 55 


\section{INTRODUCTION}

Over the last three decades, several studies have been conducted in Kuwait, which showed that anemia and obesity are the most common nutritional disorders among different age groups. Nutritional problems prevailing in Kuwait varies from undernourishment (anemia) to over nourishment (overweight) and are associated with health complications such as diabetes, hypertension, and heart diseases (Ministry of Health, 1996).

The prevalence of obesity among adult Kuwaiti males and females has been reported to be $24.6 \%$ and $47.9 \%$, respectively (Al-Awadi \& Amine, 1989). Among school children, the prevalence of obesity has been reported to be $18 \%$ and $27 \%$ for boys and girls, respectively (Eid, Al-Hooti, \& Khalafawi, 1986), indicating that the problem of obesity in Kuwait begins at a young age. Overweight children have a high risk of being overweight in adulthood and therefore are also at risk from the associated health complications such as hypertension and coronary heart disease and mortality (Power, Lake, \& Cole 1997; Nieto, Szklo, \& Comstock, 1992).

The role of the home environment in the development of childhood obesity has been recognized for a long time; nonetheless, few studies have documented the extent to which the home environment contributes to childhood obesity. A family history of being overweight is an important indicator of genetic risk (Richard \& Knight, 1999). It has been proposed that the primary determinants of infant body weight at 12 months of age are predisposed by their mothers' obesity or leanness (Roberts, Savage, Coward, Chew \& Lucas, 1988). 
Anemia has also been reported to be prevalent among various population groups in Kuwait. Mostafa and Nuwayhed (1979) reported that about $75 \%$ of children aged 1-24 months and $40.7 \%$ of children aged $25-60$ months had hemoglobin $(\mathrm{Hb})$ concentrations of less than $11 \mathrm{~g} / \mathrm{dl}$. In 1985, the Ministry of Health in Kuwait studied 1,311 women over 21 years of age and found that $41.6 \%$ were anemic (Hb values below $12 \mathrm{~g} / \mathrm{dl}$ ). A more recent study by Al-Awadi, Amine and Goulam (1995) assessed 980 Kuwaiti women between the ages of $14-45$ years and found that $23.2 \%$ of the women were anemic. Anemia is the most prevalent nutritional problem in the world. More than 2.1 billion people are anemic worldwide (DeMaeyer \& Adiels-Tegman, 1985). In the human body, iron is present in all cells and has several vital functions such as serving as a carrier of oxygen to the tissues from the lungs via the hemoglobin $(\mathrm{Hb})$. In infants (children aged 0-12 months) and preschool children (children aged 1-5 years), irondeficiency anemia may result in developmental delays and behavioral disturbances (e.g., decreased motor activity, social interaction, and attention to tasks). These developmental delays may persist past school age (i.e., 5 years) if the iron deficiency is not fully reversed (Idjradinata \& Pollitt, 1993). Research has indicated that the rapid rate of growth coinciding with inadequate intake of dietary iron place children less than 24 months, particularly those 9-18 months, at risk for iron deficiency (Yip, 1989). Lack of proper knowledge about nutrition and dietary requirements, poor food habits, and lack of physical activity have led to the development of health problems in Kuwait (Al-Shawi, 1985). The association of various dietary practices of family life with obesity in childhood is well established, but less is known about the effect of these influences on the risk of obesity later (Lissau \& Sorensen, 1994). 
Research that examines types of infant feeding practices, socioeconomic status (SES), and number of pregnancies of Kuwaiti mothers in relationship to their Body Mass Index (BMI), hemoglobin ( $\mathrm{Hb}$ ) and their infants' (ages 2-23 months) Hb levels is lacking. By studying certain nutritional disorders such as obesity and anemia of mothers, and how they might affect their infants, one becomes more aware of those conditions and their consequences. For example, the health problems associated with obesity in Kuwait are diabetes mellitus, hypertension, hyperlipidemia, certain cancers, and gout (Al-Awadi \& Amine, 1989). Moreover, health problems associated with irondeficiency anemia in children under five years old are developmental delays and behavioral disturbances (e.g., decreased motor activity, social interaction, and attention to tasks) (Idjradinata \& Pollitt, 1993).

The purpose of the study was to provide data on the body mass index (BMI) and hemoglobin $(\mathrm{Hb})$ levels of Kuwaiti women and how the factors impact the nutritional status of their infants. This information can enable Kuwaiti dietitians to develop preventive approaches to overweight or obesity and anemia, thus improving the quality of life for women and infants. 


\section{REVIEW OF LITRATURE}

\section{Background on Kuwait}

Kuwait, an oil-rich Arab country with an area of $17,818 \mathrm{sq} . \mathrm{km}$ is located at $30.27^{\circ} \mathrm{N}$ and $48.46^{\circ} \mathrm{E}$. It is bordered on the north and west by Iraq, on the south by Saudi Arabia and on the east by the Arabian Gulf. The total population is about two million, however, only about 700,000 are Kuwaiti citizens. Kuwait is divided into five administrative divisions called governorates. Its citizens have a high standard of living that includes free education, medical care, and other amenities. The discovery of oil in the 1950s has brought dramatic changes in living standards, including changes in lifestyle, food habits, and food consumption patterns. Kuwait has a high per capita income (estimated at $\$ 22,300$ in 1995). Thus, Kuwait is one of the wealthiest countries in the Gulf and the world (Ministry of Information, 1996).

The Infant Mortality Rate is 10.7 per 1000 live births, and life expectancy is 73.8 years. The life expectancy of females exceeds that of males. As in other developed countries, cardiovascular diseases, cancers, and traffic accidents have now become the leading causes of death (Ministry of Information, 1996). The significant number of cardiovascular and traffic accident deaths are probably reflective of the increased incidence of obesity and hanging lifestyles in an affluent society in which many people can afford motor vehicles and have generally sedentary lifestyles (Ministry of Information). Diabetes Mellitus, asthma, and hereditary hemolytic anemia were reported to be the fourth leading causes of morbidity in governmental hospitals in 1993 (Ministry of Information). 
The flow of oil revenues since 1946 has affected the lifestyles of Kuwaiti society as well as its economic and social structures. With modernization, many profound changes have occurred within the family structure. The extended family system is moving toward a nuclear pattern. The majority of Kuwaiti women are now educated and not content with domestic lifestyles nor being confined to their homes. New educational and occupational opportunities and the emergence of modern and affluent role models offer more for them now (Al-Bustan \& Kohli, 1998).

Amine and Al-Awadi (1992) have investigated the impact of family income on meal patterns in Kuwait. They found that the most common foods consumed by lowincome families at breakfast were milk, cheese, fried or boiled eggs, and pita bread, while those consumed by high-income families were fresh milk, orange juice, and cornflakes. At lunch, plain yogurt and a dish composed of lamb or chicken, rice, vegetable oil, and mixed spices were more likely to be consumed by low-income families; while fruits and salads, and a dish composed of fish or shrimp, rice, vegetable oil, and mixed spices were more likely to be consumed by high-income families. At dinner, fried chicken, macaroni, fried potatoes, and falafel were the most common choices among low-income families; while hamburgers and steaks were more frequently consumed by high-income families. High-income families consumed mostly fruits, salads, and tea or fresh juice as a snack between meals; while sandwiches and tea or carbonated beverages were consumed by low-income families.

\section{Prevalence of Overweight in Kuwait and Other Countries}

Al-Harbee (1994) assessed the growth and development of 124 Kuwaiti toddlers under the ages of 36 months. The results showed that the average height and weight for 
toddlers under 18 months of age was $76.8 \mathrm{~cm}$, and $10.4 \mathrm{~kg}$, respectively. For the age group 18 to 29 months, the average height was $83.5 \mathrm{~cm}$, and the weight was $11.4 \mathrm{~kg}$. Children between the ages of 30 to 36 months had an average height of $93.4 \mathrm{~cm}$, and an average weight of $14.1 \mathrm{~kg}$. These growth averages were found to be within normal limits when compared with American standards. Al-Isa and Moussa (1998) conducted a random sample of 7,419 Kuwaiti children (3,749 boys and 3,670 girls) to assess the level of obesity among Kuwaiti pre-school children aged 0-5 years and compared their nutritional status with the National Center for Health Statistics (NCHS/CDC) reference population. They found that the rate of obesity was $8.2 \%$ ( $7.5 \%$ in males and $9.0 \%$ in females). Underweight and short stature were found to be similarly distributed among both genders. When Al-Isa and Mousa compared Kuwaiti children with the NCHS/CDC reference population, they found that Kuwaiti children were slightly heavier and shorter than American children.

Al-Isa and Moussa (2000) repeated their study with school children. They randomly selected a sample of 8,957 children aged 6-10 years $(4,401$ males and 4,556 females) from Kuwaiti elementary schools. They assessed the nutritional status of Kuwaiti children in comparison with the NCHS/CDC American reference population. The results of their study showed that obesity was significantly $(\mathrm{P}<0.01)$ higher in males than in females. Underweight was equally prevalent among both genders. When compared with the NCHS/CDC American reference population, Kuwaiti children aged 610 were significantly heavier and shorter than American children.

A survey conducted by Eid, Al-Hoofi, Bourisly and Khalafawi (1984) with 4,175 school boys and girls (6 to 17 years of age) in government schools revealed that $65 \%$ of 
the students were adequately nourished, $11 \%$ were underweight, and $22 \%$ were overweight. Underweight was more prevalent among the younger children (6-9 years old). The derived values for muscle and fat mass areas for school children were compared with the respective derived values for American children. Schoolboys showed smaller muscle and fat mass than their American counterparts, especially among adolescents. No marked difference was observed in muscle and fat mass for girls in either population.

Amine and Al-Awadi (1986) assessed the nutritional status of 241 male and 240 female fourth grade students, with a mean age of 14.5 years. The results showed that $33.5 \%$ of the students were underweight, $44.5 \%$ were within normal weight, $11.9 \%$ were overweight, and $10.2 \%$ were obese. Underweight was more prevalent among boys, while obesity was more common among girls.

Al-Isa (1995) revealed that the prevalence of obesity (BMI > 30) among Kuwaiti adults was common. Approximately $70.2 \%$ of adults had BMIs greater than 25 ; among women and men the rate of obesity was $72.9 \%$ and $67.5 \%$, respectively, and $32.3 \%$ of men and $40.6 \%$ of women had BMIs greater than 30 .

A rapid increase in the prevalence of obesity in children has been reported in the United States, England, and around the world (Martorell, Kettel-Khan, Hughes \& Grummer-Strawn, 2000). Zuguo et al. (1998) determined that overweight is increasing among preschool children under the age of five years in the US among low-income populations. Based on the weight-for-height 85 th percentile cut-off-point, the prevalence of overweight among children ages 0 to 59 months increased from $18.6 \%$ in 1983 to 
$21.6 \%$ in 1995 , and from $8.5 \%$ in 1983 to $10.2 \%$ in 1995 , based on the weight-for-height 95th percentile cutoff point.

Bundred, Kitchiner and Buchan (2001) determined trends in weight, height, and BMI among children in England; 35,662 infants aged 1-3 months and 28,768 children aged 2.9-4.0 years were studied from 1989 to 1998 . They found a highly significant $(\mathrm{P}<0.001)$ increase in the proportion of overweight children $(14.7 \%$ to $23.6 \%)$, obese children $(5.4 \%$ to $9.2 \% ; \mathrm{P}<0.001)$, and $\mathrm{BMI}$ in children under four years of age during this period.

Overweight and Infant Feeding Practices

The appropriate timing of complementary feeding for breast-fed infants in developing countries is a controversial topic. Many studies have demonstrated that the growth of such infants appears to falter as early as 2-3 months of age when compared with current reference data (Waterlow, Ashworth \& Griffiths, 1980). With respect to children's eating and energy balance, a few studies have shown that the parents' diet history, eating concerns, and child feeding practices influence the development of their children's eating behaviors and weight outcomes (Ruther \& Richman, 1993).

It has been shown that the type of infant feeding practices can influence the growth of healthy infants during the first year of life (Dewey, Peerson \& Brown, 1995). Differences in the growth pattern of breast-fed and formula-fed infants are well recognized and have been attributed to differences in nutrient intake. Recent studies from a North American survey and northern European countries comparing infants' growth with the National Center for Health Statistics-World Health Organization (NCHS-WHO) reference data in the first year of life ("12 month breast fed pooled dataset") have 
identified different patterns in breast-fed and formula-fed infants. Breast-fed infants show a more rapid growth in the first two months and less rapid growth (particularly in weight) from 3 to 12 months as compared to formula-fed infants (Dewey, Peerson \& Brown, 1995).

Agostoni et al. (1999) found that different growth patterns are more pronounced during the first six months of life between breast-fed and formula-fed infants. In the second six months of life, breast-fed infants showed a progressive decline in growth rate (particularly in those breast-fed for 12 months) while the formula-fed group showed a progressive continuous rise. Thus, a longer duration of breast-feeding is associated with a greater decline in weight for age and weight for length.

Dewey, Heinig, Nommsen, Peerson and Lönnerdal (1993) compared matched cohorts of infants either breast-fed (46 infants) or formula-fed (41 infants) for 12 months. The two cohorts were matched for parental socioeconomic status (SES), education, ethnic group, anthropometric characteristics, and for infant gender and birth weight; neither group was given solid foods before four months of age. While the mean weight of formula-fed infants remained at or above the National Center for Health Statistics median throughout the first 18 months, the mean weight of breast-fed infants dropped below the median beginning at 6 to 8 months, and was significantly lower than that of the formulafed group between 6 and 18 months (Dewey et al., 1993). In contrast, length and head circumference values were similar between groups. The groups had similar weight gain during the first three months, but breast-fed infants gained less rapidly during the remainder of the first year. 
However, Villalpando and Lopez-Alarcon (2000) found that at six months, breastfed infants were heavier (though not significantly) and tended to be taller than infants who were fed formula. At six months, the weight of breast-fed infants caught up to the weight of NCHS standards, while infants fed formula fell to around -1 NCHS-Z-score for weight and length. This study was designed to test whether breast-feeding protects infants reared in an unfavorable environment from growth stunting by averting acute infections.

\section{Other Factors Affecting Overweight}

The pattern of growth is strongly influenced by nutrition and disease, so that anthropometric measurements during the growth period of childhood and adolescence are among the most useful criteria for assessing health and nutritional status of children (Eid et al., 1984). Changes in relative fatness with age occur simultaneously with changes in fat cell size or fat cell number. During the first year of life, adiposity increases rapidly owing to the growth in the size of the adipocytes. In the following years, adipose tissue growth decreases and then remains stable for several years, while body height continues to increase. This development is reflected by a decrease in relative fatness. The onset of the second period of rapid growth in body fat is referred to as "adiposity rebound" (Rolland-Cachera et al., 1984).

By the time children reach school age, those who are overweight, especially those with an obese parent, have a high probability of being obese as adults. Because parents are the primary means by which children learn the sociocultural context of eating, it is essential to understand the family eating environment to design early interventions to prevent obesity; therefore, preventing young children from ever becoming overweight is an essential public health goal (Whitaker, Wright, Pepe, Seidel \& Dietz, 1997). Johnson 
and Birch (1994) investigated children's ability to self-regulate energy intake and to determine whether individual differences in the precision of food intake regulation are related to children's anthropometric measures. They found that children of mothers who exert a high level of control over their food intake become less able to regulate their own intake, although a mother's reaction may occur secondary to her children's inability to control their own food intake.

Stunkard, Berkowitz, Stallings and Schoeller (1999) studied 40 infants of obese mothers and 38 infants of lean mothers to determine if genetic background, parental obesity, and low total energy expenditure (TEE) influence the body weight at one year of age. Half of the subjects were boys and half girls. No significant differences between the risk groups in body size or composition at any time during the first year were observed. The TEE was not predictive of body weight, weight-for-height, fat, fat free mass, or skin fold thickness at 12 months of age. Infants of obese mothers did not differ in any measure of body size or composition from the infants of non-obese mothers. They found that infants with obese mothers who displayed more vigorous sucking behavior were significantly different in measure of body size or composition at one year of age. Roberts et al. (1988) studied 3-month old infants born to overweight or lean mothers (6 lean and 12 overweight mothers) who were recruited soon after birth. Total energy expenditure (TEE) and metabolizable energy intake were measured. Infants with both low TEE and overweight mothers became overweight as indicated by exceeding the 90th percentile of weight-for-height at one or more assessments during the first year of life, in contrast with 12 infants without these characteristics. This determined risk factors for weight gain for 
infants at high or low risk of obesity by virtue of their mothers' obesity or leanness is significant.

Whitaker et al. (1997) found that parental obesity significantly alters the risk of obesity in adulthood for both obese and non-obese children, especially those under ten years of age. Prior to three years of age, the primary predictor of obesity in adulthood was the parent's obesity status; the child's obesity status was not an indicator of adult obesity. For children 3-9 years of age, the child's and the parents' obesity status were both important predictors, but as the child aged, the child's obesity status became a more important predictor. Especially before six years of age, obesity in both parents substantially increased the odds of the child becoming an obese adult. Whitaker, Deeks, Baughcum and Specker (2000) examined parents of 85 White children at 36 months of age ( 49 boys and 36 girls) for the association between children's adiposity and their parents' eating behaviors and BMI. There were no significant relationships between the children's percentage of body fat and parent eating scores. The correlation between the children's percentage of body fat and parent BMI was significant only between mothers and daughters $(\mathrm{P}=0.04)$.

Moussa (1994) studied the effects of a number of factors believed to be associated with and possibly cause related to the occurrence of obesity among 220 children (120 males and 100 females) aged 7 to 18 years in the United Arab Emirates. The results showed that the mother's education, family history of obesity, and physical activity were significant determinants for obesity.

Moussa et al. (1999) investigated the association between social, familial and behavioral factors with childhood obesity. Obese school children (230 boys and 230 
girls) aged 6 to 13 years old were matched by age and gender to 460 normal weight controls. The results showed that a family history of obesity, diabetes mellitus, and associated diseases (respiratory and bone diseases) in children were significantly associated with obesity after adjusting for social and behavioral factors such as SES and breast-feeding in infancy. A prospective population-based study examined the influence of parental care in childhood on the risk of obesity in the offspring in young adulthood (Lissau \& Sorensen, 1994). Dirty and neglected children had a much greater risk of adult obesity than adequately groomed children. However, being an only child, receiving overprotective parental support, and/or being well groomed have no effect. Parental neglect during childhood predicts a greater risk of obesity in young adulthood, independent of age and body-mass index in childhood, gender, and social background.

Six hundred twenty-two mothers with children 23 to 60 months of age were studied by Amy, Baughcum, Chamberlin, Deeks and Whitaker (2000) to determine the factors that are associated with the mothers' failure to perceive when their preschool children are overweight. They found that obesity (body mass index: $\geq 30 \mathrm{~kg} / \mathrm{m}^{2}$ ) was more common in the low education group of mothers (30\% vs. $17 \%)$, and their children tended to be more overweight (weight-for-height percentile: $\geq 90$ th; $19 \%$ vs. $14 \%$ ). About $79 \%$ of mothers failed to perceive their overweight child as being overweight. Among the 99 mothers with overweight children, low maternal education was associated with a failure to perceive their children as being overweight. Nearly all of the obese mothers regarded themselves as overweight, however, the majority of them did not view their overweight children as being overweight, and this misperception was more common in mothers with less education. 
A random sample of 2,999 adult females was studied by Amine and Al-Awadi (1989) to investigate the prevalence of obesity among females. The results showed that $2.4 \%$ of them were underweight, $52.5 \%$ were overweight, and $42 \%$ were obese. The obesity was least common among young females under 20 years of age (20.6\%), and it increased in older females (57.2\%). Obesity was lower among females with a technical profession, and most prevalent among non-working females, followed by those having a management job. The prevalence of obesity was increased as the family size increased, rate of obesity reached $48.4 \%$ when the family size was more than seven, and dropped to $22.4 \%$ when the family size was less than four. Obesity was more prevalent in families with low incomes (56.3\%) than those with high incomes (33.5\%). A similar pattern was found with the number of children.

Another random sample of 2004 Kuwaiti families was taken by Amine and AlAwadi (1990) whose investigation was to determine the role of a maid and her nationality on the nutritional status of mothers. Housemaids are employed in Kuwaiti homes even when the mother is not employed. They found that the impact of the presence of a maid on obesity was significantly associated with over nutrition $(\mathrm{P}<0.01)$ among Kuwaiti mothers. The prevalence of obesity was $44.7 \%$ when maids were employed, and decreased to $35.4 \%$ without maids. The presence of maids resulted in a reduction in the physical activities that might have been exerted by the mothers at home.

A study conducted by Wisemandle, Maynard, Guo, and Diervogel (2000) consisted of 67 males and 47 females in overweight groups during early childhood, 62 males and 48 females in overweight groups during early adolescence, and 80 males and 114 females in never having been overweight groups. This study found that weight 
and BMI in males and females with early overweight were significantly greater than in those who never became overweight or those with late overweight, beginning at the time of adiposity rebound. This early-onset group had adiposity rebound at younger ages than did the other groups, and continued growth was such that weight and BMI began to cross national percentile levels.

In many societies, obesity has become a major challenge to public health officials as it has been linked to the increased incidence of several chronic diseases (morbidities). Nowadays, it is well recognized that obesity is a significant risk factor for the development of diabetes mellitus, hypertension, coronary heart disease, osteoarthritis, gall bladder disease, stroke, respiratory disease, and colon cancer (Kuczmarski, Flegal, Campbell, \& Johnson, 1994). As BMI increases, especially above $30 \mathrm{Kg} / \mathrm{M}^{2}$, the risk of chronic diseases increases. The trend in the mortality and morbidity from obesityrelated diseases in Kuwait are similar to Western countries. The health problems associated with obesity in Kuwait are diabetes mellitus, hypertension, hyperlipidemia, certain cancer, and gout diseases (Al-Awadi \& Amine, 1989).

\section{Prevalence of Anemia in Kuwait and Other Countries}

Anemia is the most prevalent nutritional problem in the world. More than 2.1 billion people are anemic worldwide (DeMaeyer \& Adiels-Tegman, 1985). In a study by Najwa, Himadri, Thomas, and Adekunle (2000), data indicated that anemia is more common among hospitalized children and among younger children in Kuwait. They examined a total of 267 children (153 males and 114 females) aged 6-144 months, who were admitted to a hospital for acute medical problems. They found that the prevalence 
of anemia among these children was about $36.7 \%$. Jackson, Al-Moosa, Mughah, and Nkansa (1999) studied 2283 healthy 2-6 year old Kuwaiti preschoolers and secondary school adolescent girls, selected from schools in all five Kuwaiti Governates, to determine the prevalence and etiology of anemia. They found that the prevalence of anemia in the 2- and 3-year-old age groups to be $39 \%$ and $28 \%$, respectively, but declined substantially to $18 \%$ in the 4 - and 5-year-old groups, while increasing to $44 \%$ in the 6-year-old age group, and $29.5 \%$ of the adolescent girls.

In a cross-sectional study, Eid et al. (1986) assessed the prevalence of anemia in 1,208 school-aged children in Kuwait (6-17 years old). After blood hemoglobin contents were measured, the results revealed that anemia was about twice as prevalent among girls as boys $(25.7 \%$ vs. $12.8 \%)$, and it was more prevalent among younger boys and adolescent girls than among other children. In another cross-sectional sample of 1,051 healthy adolescent schoolgirls in Kuwait, Jackson and Al-Mousa (2000) examined the prevalence of anemia and found that $30 \%$ of the girls were anemic.

A nutrition survey was performed by Hassan, Sullivan, Yip, and Wooder (1997) in 1990 among children 6-35 months of age living in Palestinian refugee camps in the Middle East (Syria, Jordan, the West Bank, Gaza Strip and Lebanon). Overall, 67\% were anemic, ranging from $54 \%$ in the West Bank to $75 \%$ in Syria. In inner cities in the United Kingdom (UK), iron deficiency anemia occurs in infants with the same frequency as in developed countries such as the USA, France, and Japan. A nationally representative UK sample suggests a current prevalence of $12 \%$ of 1.5 to 2 year olds with hemoglobin less than $11 \mathrm{~g} / \mathrm{l}$. However, in socioeconomically deprived populations, the 
prevalence of iron deficiency anemia among children 6 to 24 months currently varies between $25-40 \%$.

\section{$\underline{\text { Anemia and Infant Feeding Practices }}$}

The American Academy of Pediatrics (1978) and other organizations endorse breast-feeding as the preferred source of infant nutrition for infants younger than six months of age because of its proven benefits to infants and their mothers. Human milk is the recommended food for healthy newborns. It provides optimal nutrition, contains phagocytic and immunocompetent cells, and promotes intestinal mucosal maturation.

Information from other studies suggested that exclusive breast-feeding is protective against iron deficiency for infants $<6$ months of age, after which the iron concentration in breast milk may not meet the infant's iron requirement (Dallman, Siimes, \& Stekel, 1980). Calvo, Galindo, and Aspres (1992) evaluated the iron status of infants exclusively breast-fed for a prolonged period in relation to their growth rate. They studied 40 infants ( 25 breast-fed; 15 formula-fed) from 0 to 9 months of age. Breast-feeding or bottle-feeding was the only source of food during the first six months. They found that at the ninth month, prevalence of anemia was $27.8 \%$ in the breast-fed group and $7.1 \%$ in the formula-fed group. Therefore, infants who are exclusively breast-fed for nine months need an additional source of iron after about six months of age (DHHS, 1992).

The early introduction of unmodified cow's milk as the major milk source at around six months of age is the most common dietary characteristic of infants found to have iron deficiency anemia at one year of age (Sadowitz \& Oski, 1983). Mira et al. (1996) studied young children aged 12-36 months in order to compare their intakes of heme and non-heme iron in 56 iron-depleted and 68 iron-repleted children. The results of 
this study showed that iron-depleted children had a significantly lower intake of heme iron than iron-repleted children $(\mathrm{P}=0.012)$. Iron-depleted children had cow's milk introduced before the age of one year.

Breast-feeding has always been a popular practice in Kuwait. According to Islamic rules, the mother is invited to breast-feed her infant for a period of two years. A random sample of 2,994 mothers of infants under two years of age was studied by Amine and Al-Awadi (1989). They investigated the types of infant feeding practices. The prevalence of breast-feeding was $13.9 \%$ among first order children, $26.7 \%$ for the second child, and increased to $35.7 \%$ among later order children. The infant feeding patterns were significantly modified by the mothers' education $(\mathrm{P}<.05)$. Infants of illiterate mothers received breast or bottle-feeding at similar rates (38.5\%); however, the rate of mixed-feeding was least common (23.3\%) among illiterate mothers, and most common (39.3\%) among mothers who held a university degree.

\section{Other Factors Affecting Anemia}

Iron deficiency anemia (IDA) is an important public health issue for children as it is the most common nutritional disorder in early childhood (Scrimshaw, 1984). Late infancy, particularly ages 9-18 months and early childhood (under 5 years of age), are high-risk periods for iron deficiency because of an increased iron requirement related to rapid growth and diets that are relatively low in iron content. Breast-feeding after six months of age without iron supplementation, and use of non-iron fortified cow's milk as weaning food are considered risk factors associated with the development of anemia among children at this age (Hassan et al., 1997). 
In infants (0-12 months) and preschool children (1-5 years), iron-deficiency anemia results in developmental delays and behavioral disturbances (e.g., decreased motor activity, social interaction, and attention to tasks). These developmental delays may persist past school age (i.e., 5 years) if the iron deficiency is not fully reversed (Idjradinata \& Pollitt, 1993). The effects of childhood anemia during the adults years include "retardation of physical and mental development, fatigue and low productivity at work, and ... impairment of reproductive functions" (Scrimshaw, 1984). Long-term or severe iron deficiency may not respond to iron therapy and may be associated with poorer outcomes at long-term follow-up even after iron therapy (Lozoff, Jimenez, \& Wolf, 1991).

Amine and Al-Awadi (1987) investigated the prevalence of anemia among 980 adult females from different Kuwaiti Governorates. They found that the prevalence of anemia was least common among younger age group females under 20 years old (15.2\%) and greater among older females $(27.8 \%)$. The prevalence of anemia was relatively low among underweight and normal weight females, $18.3 \%$ and $21.3 \%$, respectively, and it increased to $27.5 \%$ among overweight and obese females. Anemia was least prevalent when females had no children (19.5\%), $24.7 \%$ when females had three children or less, and increased to $27 \%$ when the females had more than four children.

A total of 120 infants at 6 and 12 months of age and 110 toddlers at 18 and 24 months of age in three neighborhoods in a Western part of Jerusalem were studied by Palti, Adler, and Rashef (1977). They found the median hemoglobin level at nine months was lower than at 24 months in all three neighborhoods. The median was higher in the 
middle class than in the poor neighborhoods, and the rate of anemia lower and less severe among the middle class as compared to the poor neighborhoods. 


\section{METHODOLOGY}

The purpose of this study was to evaluate the problems of obesity and anemia among Kuwaiti mothers and their infants ages 2 to 23 months. Body mass index (BMI) and hemoglobin levels of mothers were measured as associated to obesity and anemia among their infants. In addition, this study examined the prevalence of the types of infant feeding practices, and assessed the body weight and hemoglobin levels of infants using the types of infant feeding practices. Other factors that might influence this population were the education levels and occupations of mothers; furthermore, the number of pregnancies that these Kuwaiti women have experienced were also studied. Preventing overweight or obesity and anemia among the Kuwaiti mothers and infants will improve the quality of life for this population.

The specific objectives of the study were to:

- Assess the prevalence of obesity and anemia for a group of Kuwaiti mothers and infants aged 2-23 months.

- Assess the prevalence of infant feeding practices: breast-feeding, formula feeding, and mixed-feeding among a group of Kuwaiti mothers with infants.

- Compare the growth rate of these Kuwaiti infants to the NCHS/CDC standards.

- Correlate the BMI and hemoglobin levels of mothers with their infants.

- Determine the differences in the body weight and hemoglobin levels of infants who are breast-fed, formula-fed, or mixed-fed. 
- Evaluate the association of factors such as education, occupation, and number of pregnancies with maternal and infant obesity and anemia among this study population.

This research will attempt to answer the following questions:

I. Questions regarding the mothers and infants:

1. Is the distribution of the weight-for-age, and height-for-age of the infants within normal range compared to established growth standards for the U.S. population?

2. What is the distribution of Body Mass Index (BMI) of the mothers in categories of underweight, normal, overweight, or obese?

3. Are the average hemoglobin $(\mathrm{Hb})$ levels of infants and mothers comparable to the World Health Organization standards?

4. What is the prevalence of the following feeding practices: breast-feeding, bottlefeeding, or mixed-feeding?

II. Questions regarding the infants:

1. Is there a relationship between the mothers' BMI and their infants' weight and height?

2. Is there a relationship between the mothers' $\mathrm{Hb}$ and their infants' $\mathrm{Hb}$ ?

3. Does the educational level or occupational status of a mother influence weight and/or $\mathrm{Hb}$ level of her infant?

4. Do types of infant feeding practices influence weight and/or $\mathrm{Hb}$ levels of infants?

5. Is there a relationship between the infant's $\mathrm{Hb}$ level and age; $\mathrm{Hb}$ level and weight? 
II. Questions regarding the mothers:

1. Does the educational level or occupational status of the mother correlate with her $\mathrm{BMI}, \mathrm{Hb}$ level, and number of pregnancies?

2. Does the educational level or occupational status of the mother influence the type of infant feeding practice(s)?

3. Is the number of pregnancies related to BMI, $\mathrm{Hb}$ level, and/or type of infant feeding practice?

The following are the hypotheses to be tested by this research project:

- High incidence of overweight or obesity and anemia among infants will be associated/ correlated with the high BMI and low $\mathrm{Hb}$ levels of their mothers, respectively.

- Breast-fed infants will have a lower body weight and lower $\mathrm{Hb}$ levels than infants who are formula-fed.

- There will be an inverse relationship between the mothers' education and occupation and their BMI and the weight of their infants, and a positive relationship with the $\mathrm{Hb}$ levels of mothers and infants.

- Incidence of overweight or obesity and anemia will be more prevalent among multiparous mothers.

Study Population: The sample was made up of 254 mothers and their infants (127 boys and 127 girls) who were between the ages of 2 to 23 months. Only apparently healthy Kuwaiti mothers and infants were included in the study; those pregnant or suffering from chronic diseases that could affect hemoglobin levels and growth were excluded. 
Study Setting: The sample covered all five Governorates in Kuwait, which include Capital, Hawalli, Farwania, Ahmadi, and Jahra. From January 2000 through November 2000 the Department of Food and Nutrition Administration of the Ministry of Health collected the data from all five Governorates. Mothers and infants were selected from those attending the Health Centers for minor ailments such as cold, flu, headache, etc.

Methodology: Infants' ages and gender were recorded. The infant's date of birth was obtained from the mother. The age of the infant was rounded off to the nearest month, for example, 12 months and 20 days were considered 13 months. The infants' heights and weights were measured as part of the routine examination at the health centers. Weights were measured to the nearest $0.1 \mathrm{~kg}$ using a Seca Electronic Balance and measuring height to the nearest $0.1 \mathrm{~cm}$ using a stationary height board calibrated in $\mathrm{cm}$. The hemoglobin $(\mathrm{Hb})$ levels of mothers and their infants were determined from capillary blood obtained from infants and mothers by using a finger stick. During the interviews, the mothers were asked about the type of infant feeding practices, number of pregnancies, educational level, and occupation. The education and occupation of the mothers were classified as follows:

Education:

$1=$ Illiterate, 2 = Primary (Read and Write), $3=$ Intermediary, $4=$ Secondary, $5=$ PostSecondary Diploma, $6=$ University, and $7=$ Post-Graduate 
Occupation:

$0=$ Retired, 1 = Administration (e.g., Managers, Directors...), 2 = Professionals (e.g., Doctors, Engineers, Lawyers, Teachers...), 3 = Clerks, $4=$ Technical (e.g., Technicians, Typists, Secretaries...), $5=$ Soldiers, $6=$ Students, 7 = Business (e.g., Traders, Company owners, Landlords...), $8=$ Maids, and $9=$ Housewives.

Ancillary Study:

This ancillary study was conducted using data collected by the Department of Food and Nutrition Administration at the Ministry of Health in Kuwait. Permission was granted to the investigator to utilize the data for developing this proposal and research for the master's thesis. The data had never been utilized by anyone before for publication purposes.

In order to make comparisons, the reference curves of the National Center for Health Statistics/Centers for Disease Control (NCHS/CDC) were used as international growth references. Weight-for-age and weight-for-height were calculated separately for distributions below and above the median. Also, the World Health Organization (WHO) standards for definition of anemia were used.

The definition of under, normal, and overweight among infants was based on the respective growth curve for age and gender derived from data of the Third National Health and Nutrition Examination Survey (NHANES III). Underweight in children was defined as weight-for-height less than the $5^{\text {th }}$ percentile, normal weight as weight-forheight between the $5^{\text {th }}$ and $95^{\text {th }}$ percentiles, and overweight as weight-for-height above the $95^{\text {th }}$ percentile. Short stature was defined as height-for-age less than the $5^{\text {th }}$ percentile, 
normal height as height-for-age between the $5^{\text {th }}$ and $95^{\text {th }}$ percentiles, and tall as heightfor-age above the $95^{\text {th }}$ percentile (Dibley, Goldsby, Staehling, \& Trowbridge, 1987). The Body Mass Index (BMI) $\left(\mathrm{kg} / \mathrm{m}^{2}\right)$ of mothers were calculated from weight and height measures and used to establish obesity. Maternal BMI was categorized based on the WHO/ Department of Health and Human Services guidelines, which are as follows: low (BMI < 19.9), normal $(20.0<\mathrm{BMI}<24.9)$, overweight $(25<\mathrm{BMI}<29.9)$, obese $(30<$ $\mathrm{BMI}<39.9)$, and severe obese $(\mathrm{BMI}>40)(\mathrm{WHO}, 1988)$.

The WHO standards for anemia state that when an infant's hemoglobin value is less than $11 \mathrm{~g} / \mathrm{dl}$, and when the mother's hemoglobin value is less than $12 \mathrm{~g} / \mathrm{dl}$, the individual is considered anemic (WHO, 1968).

The following age groups for infants were used: 2-5, 6-11, and 12-23 months. Infant feeding practices were assessed and categorized as: 1) breastfeeding-all nourishments from breast milk; 2) formula feeding-all nourishments from infant formula, delivered by a bottle; and 3) mix-feeding, combining breastfeeding and bottle-feeding. Socioeconomic factors based on maternal education and occupation were analyzed. The highest level of education attained by the mother was used as a marker for social class. Also, the number of pregnancies were used as a family size and were categorized as 1) 1 to 2 pregnancies-small family size; 2) 3 to 5 pregnancies-medium family size; and 3) six and above pregnancies-large family size.

Data Analysis:

Statistical analysis such as descriptive, correlations, cross tabulations, and oneway analysis of variance were performed on age and gender of infant, BMI and $\mathrm{Hb}$ of 
mothers and infants, educational level and occupational status of mothers, type of feeding practice, and number of pregnancies. For significant one-way analysis of variance tests, Tukey's post hoc tests were used to compare pairs of groups. The analysis was conducted by using the SPSS. Statistical significance was set at $\mathrm{P}<0.05$. 


\section{RESULTS}

Demographic Characteristics of the Participants

The sample used in this study consisted of 254 Kuwaiti mothers and their respective infants. The sample was purposely selected to include an equal number of infant boys and girls. The infants ranged in age between 2 to 23 months. Only apparently healthy mothers and infants were included in the study. Mothers who were pregnant or suffering from chronic diseases that could affect the hemoglobin $(\mathrm{Hb})$ levels and/or growth rate of the infants were excluded.

Table 1 shows the sociodemographic characteristics of the participants. The distribution of infants by age group is presented in Table 2 . Eighty $(31.5 \%)$ of the infants ( 40 boys and 40 girls) were in the $2-5$ months age group. Seventy-eight $(30.7 \%)$ of the infants ( 39 boys and 39 girls) were in the 6-11 months age group, and finally, 96 (37.8\%) infants ( 48 boys and 48 girls) were in the12-23 months age group. The combined mean $( \pm \mathrm{SD})$ age of the infants was $9.6 \pm 5.9$ months. Table 3 shows comparisons of age, weight, height, and hemoglobin between boys and girls. The comparisons of age, weight, height, and hemoglobin between boys and girls by age grouping is presented in Table 4 . There were no significant differences between the boys and girls.

The Distribution of the Weight and Height of Kuwaiti Infants

Tables 5 and 6 show the distribution of the weight and height of Kuwaiti infants according to the National Center for Health and Statistics reference. The growth 
Table 1: Characteristics of the Study Participants.

\begin{tabular}{|c|c|c|c|}
\hline Subjects & Mean \pm SD & Minimum & Maximum \\
\hline \multicolumn{4}{|l|}{ Infants: } \\
\hline Age (months) & $9.64 \pm 5.90$ & 2.0 & 23.0 \\
\hline Weight (kg) & $8.99 \pm 2.28$ & 4.4 & 15.2 \\
\hline Height $(\mathrm{cm})$ & $71.45 \pm 8.50$ & 53.0 & 90.6 \\
\hline Hemoglobin & $11.57 \pm 1.08$ & 6.5 & 14.1 \\
\hline \multicolumn{4}{|l|}{ Mothers: } \\
\hline Age (years) & $30.23 \pm 5.60$ & 19.0 & 45.0 \\
\hline Weight $(\mathrm{kg})$ & $74.49 \pm 12.90$ & 37.0 & 126.5 \\
\hline Height $(\mathrm{cm})$ & $159.05 \pm 5.39$ & 140.0 & 176.0 \\
\hline BMI & $29.44 \pm 4.88$ & 18.9 & 51.6 \\
\hline Hemoglobin & $12.93 \pm 1.37$ & 8.0 & 16.8 \\
\hline Number of pregnancies & $3.92 \pm 2.18$ & 1.0 & 10.0 \\
\hline
\end{tabular}


Table 2: Distribution of Infants by Age Group.

\begin{tabular}{|l|c|c|}
\hline $\begin{array}{l}\text { Age Grouping } \\
\text { (months) }\end{array}$ & $\begin{array}{c}\text { Frequency } \\
(\mathrm{N})\end{array}$ & $\begin{array}{c}\text { Percent } \\
(\%)\end{array}$ \\
\hline $2-5$ & 80 & 31.5 \\
$6-11$ & 78 & 30.7 \\
$12-23$ & 96 & 37.8 \\
& & \\
\hline Total & 254 & 100.0 \\
\hline
\end{tabular}


Table 3: Comparisons of Age, Weight, Height, and Hemoglobin by Gender.

\begin{tabular}{|c|c|c|}
\hline Infants & $\mathrm{N}$ & Mean \pm SD \\
\hline Age (months): & 127 & $9.79 \pm 5.98$ \\
Boys & 127 & $9.49 \pm 5.85$ \\
Girls & 127 & \\
Weight (kg): & 127 & $9.27 \pm 2.23$ \\
Boys & 127 & $8.72 \pm 2.31$ \\
Girls & 127 & $70.50 \pm 8.75$ \\
Height (cm): & & \\
Boys & 127 & $11.59 \pm 1.11$ \\
Girls & & \\
Hemoglobin (g/dl): & & \\
Boys & & \\
Girls & & \\
& & \\
& & \\
\end{tabular}


Table 4: Comparisons of Age, Weight, Height, and Hemoglobin by Gender.

\begin{tabular}{|c|c|c|c|}
\hline $\begin{array}{c}\text { Age and gender } \\
\text { (months) }\end{array}$ & $\begin{array}{l}\text { Weight }(\mathrm{kg}) \\
\text { Mean } \pm \text { SD }\end{array}$ & $\begin{array}{l}\text { Height }(\mathrm{cm}) \\
\text { Mean } \pm \mathrm{SD}\end{array}$ & $\begin{array}{c}\text { Hemoglobin }(\mathrm{g} / \mathrm{dl}) \\
\text { Mean } \pm \text { SD }\end{array}$ \\
\hline \multicolumn{4}{|l|}{$2-5$} \\
\hline Boys & $6.83 \pm 1.04$ & $63.60 \pm 3.44$ & $11.46 \pm 0.92$ \\
\hline Girls & $6.39 \pm 1.02$ & $61.98 \pm 2.91$ & $11.38 \pm 1.13$ \\
\hline \multicolumn{4}{|l|}{$6-11$} \\
\hline Boys & $9.21 \pm 1.16$ & $71.18 \pm 4.04$ & $11.50 \pm 1.21$ \\
\hline Girls & $8.32 \pm 0.93$ & $67.69 \pm 3.13$ & $11.49 \pm 0.95$ \\
\hline \multicolumn{4}{|l|}{$12-23$} \\
\hline Boys & $11.34 \pm 1.38$ & $80.73 \pm 4.25$ & $11.77 \pm 1.16$ \\
\hline Girls & $10.98 \pm 1.67$ & $79.87 \pm 5.67$ & $11.73 \pm 1.10$ \\
\hline
\end{tabular}


pattern of Kuwaiti infants was compared to the NCHS reference. When examining growth rate from age 2 through 23 months, there were 11 infants (4.3\%) who were underweight, $222(87.4 \%)$ who were normal weight, and 21 (8.3\%) who were overweight. The mean weight of the infants was $8.99 \pm 2.28 \mathrm{~kg}$; the minimum weight was $4.4 \mathrm{~kg}$ and the maximum was $15.2 \mathrm{~kg}$ (Table 1). The mean weights of boys and girls were $9.3 \pm 2.2$ and $8.7 \pm 2.3 \mathrm{~kg}$, respectively (Table 3 ). An analysis of the height of the infants indicated that 235 infants $(92.5 \%)$ were of normal height, $11(4.3 \%)$ were taller, and only eight (3.1\%) were short stature according to the NCHS reference (Table 6). The mean heights of boys and girls were $72.4 \pm 8.2$ and $70.5 \pm 8.7 \mathrm{~cm}$, respectively (Table 1).

The Distribution of the BMI of Mothers

The distribution of mothers, according to their Body Mass Index, is illustrated in Table 7. The BMI, expressed in $\mathrm{kg} / \mathrm{m}^{2}$, was used to determine the incidence of overweight and obesity among mothers. Maternal BMI was categorized based on the World Health Organization's (WHO) guidelines (WHO, 1988), which are as follows: Underweight: $\mathrm{BMI}<19.9$; Normal: 20.0< BMI < 25.0; Overweight: $25.1<\mathrm{BMI}<29.9$; Obese: $30<\mathrm{BMI}<39.9$; and Severe obese: $\mathrm{BMI}>40$. Five $(2 \%)$ of the mothers were classified as underweight, 35 (13.8\%) were normal weight, $114(44.9 \%)$ were overweight, $96(37.8 \%)$ were obese, and four (1.6\%) were severely obese and had a BMI greater than 40.0. The mean BMI was $29.4 \pm 4.9$ and classified as overweight with a minimum of 18.9 and maximum of 51.6. 
Table 5: Distribution of the Weight of Kuwaiti Infants According to the NCHS ${ }^{1}$ Reference.

\begin{tabular}{|lc|c|c|}
\hline Weight $(\mathrm{kg})$ & Frequency & Percent \\
(NCHS standards) & $(\mathrm{N})$ & $(\%)$ \\
Underweight $\quad\left(\mathrm{wt}^{2}<5^{\text {th }}\right.$ percentile $)$ & 11 & 4.3 \\
Normal weight $\quad\left(5^{\text {th }}<\mathrm{wt} .<95^{\text {th }}\right.$ percentile $)$ & 222 & 87.4 \\
Overweight $\quad\left(\mathrm{wt} .>95^{\text {th }}\right.$ percentile $)$ & 21 & 8.3 \\
\hline Total & & 254 & 100.0 \\
\hline
\end{tabular}

${ }^{1}$ NCHS $=$ National Center for Health Statistics. 
Table 6. Distribution of the Height of Kuwaiti Infants according to the NCHS ${ }^{1}$ Reference.

\begin{tabular}{|c|c|c|}
\hline $\begin{array}{l}\text { Height }(\mathrm{kg}) \\
\text { (NCHS standards) }\end{array}$ & $\begin{array}{c}\text { Frequency } \\
\text { (N) }\end{array}$ & $\begin{array}{c}\text { Percent } \\
(\%)\end{array}$ \\
\hline (ht. $<5^{\text {th }}$ percentile) & 8 & 3.1 \\
\hline$\left(5^{\text {th }}<\right.$ ht. $<95^{\text {th }}$ percentile $)$ & 235 & 92.5 \\
\hline (ht. $>95^{\text {th }}$ percentile) & 11 & 4.3 \\
\hline Total & 254 & 100.0 \\
\hline
\end{tabular}

${ }^{1}$ NCHS $=$ National Center for Health Statistics. 
Table 7: Distribution of Mothers according to their BMI ${ }^{1}$.

\begin{tabular}{|ll|c|c|}
\hline BMI of mothers & & $\begin{array}{c}\text { Frequency } \\
(\mathrm{N})\end{array}$ & $\begin{array}{c}\text { Percent } \\
(\%)\end{array}$ \\
\hline Underweight & $(\mathrm{BMI}<19.9)$ & 5 & 2.0 \\
Normal weight & $(20<\mathrm{BMI}<24.9)$ & 35 & 13.8 \\
Overweight & $(25<\mathrm{BMI}<29.9)$ & 114 & 44.9 \\
Obese & $(30<\mathrm{BMI}<39.9)$ & 96 & 37.8 \\
& & & \\
Severe obese & $(\mathrm{BMI}>40)$ & 254 & 100.0 \\
\hline Total & & & \\
\hline
\end{tabular}

${ }^{1}$ BMI standards are based on the WHO/ Department of Health and Human Services guidelines. 
The Prevalence of Anemia among Mothers and Infants

Table 8 shows the prevalence of anemia among mothers and infants. The observed prevalence of anemia among Kuwaiti infants was $24.8 \%$ based on the World Health Organization (WHO) standards $(\mathrm{Hb}<11 \mathrm{~g} / \mathrm{dl})$. The mean $\mathrm{Hb}$ of boys and girls were similar, $11.6 \pm 1.11 \mathrm{~g} / \mathrm{dl}$ and $11.5 \pm 1.10 \mathrm{~g} / \mathrm{dl}$, respectively. The minimum $\mathrm{Hb}$ level was $6.5 \mathrm{~g} / \mathrm{dl}$ and the maximum was $14.1 \mathrm{~g} / \mathrm{dl}$. Table 9 shows the prevalence of anemia among boys and girls. The prevalence of anemia and differences in the hemoglobin levels of infants by age grouping are presented in Table 10 . About $27.5 \%$ of infants were anemic in the $2-5$ month age group; $26.9 \%$ were anemic in the $6-11$ month age group; and finally, about $20.8 \%$ were anemic in the $12-23$ month age group. In addition, an $18.5 \%$ prevalence of anemia was found among Kuwaiti mothers using the WHO standards $(\mathrm{Hb}<12 \mathrm{~g} / \mathrm{dl})$. The mean $\mathrm{Hb}$ of the mothers was $12.9 \pm 1.4 \mathrm{~g} / \mathrm{dl}$. The minimum $\mathrm{Hb}$ was 8.0 , and the maximum was $16.8 \mathrm{~g} / \mathrm{dl}$.

\section{The Distribution of the Education and Occupation of Mothers}

Table 11 shows the distribution of the educational levels of the mothers in the study. Seventy-five mothers (29.5\%) had at least a four-year university degree, while only $23(9 \%)$ had minimal or no education. The remaining 156 mothers $(61.5 \%)$ had an education ranging from intermediary ( 8 years) to post-secondary (14 years). It should be noted that the educational system in Kuwait is set up as a sequence of three cycles to cover the Kindergarten to $12^{\text {th }}$ grade educational continuum. In other words, a primary cycle of four years, followed by an intermediary cycle of four years, and finally, a third cycle of another four years. Upon successful completion of the three cycles, a student is 
Table 8: Prevalence of Anemia among Mothers and Infants according to WHO Standards ${ }^{1}$.

\begin{tabular}{|l|c|c|c|}
\hline Subjects & Anemic & Normal & Total \\
& $\mathrm{N}(\%)$ & $\mathrm{N}(\%)$ & $\mathrm{N}(\%)$ \\
\hline Mothers & $47(18.5)$ & $207(81.5)$ & $254(100)$ \\
& & & \\
\hline Infants & $63(24.8)$ & $191(75.2)$ & $254(100)$ \\
\hline
\end{tabular}

${ }^{1}$ WHO standards for anemia are:

Anemic: When mothers' $\mathrm{Hb}<12 \mathrm{~g} / \mathrm{dl}$, and infants' $\mathrm{Hb}<11 \mathrm{~g} / \mathrm{dl}$.

Normal: When mothers' $\mathrm{Hb}>12 \mathrm{~g} / \mathrm{dl}$, and infants' $\mathrm{Hb}>11 \mathrm{~g} / \mathrm{dl}$. 
Table 9: Prevalence of Anemia of Infants by Gender. WHO ${ }^{1}$ Standards for Anemia are:

\begin{tabular}{|l|c|c|}
\hline Infants & Anemic & Normal \\
By gender & $\mathrm{N}(\%)$ & $\mathrm{N}(\%)$ \\
\hline Boys & $30(23.6)$ & $97(76.4)$ \\
Girls & $33(26.0)$ & $94(74.0)$ \\
\hline Total & $63(24.8)$ & $191(75.2)$ \\
\hline
\end{tabular}

${ }^{1}$ World Heath Organization

Anemic: When infants' $\mathrm{Hb}<11 \mathrm{~g} / \mathrm{dl}$.

Normal: When infants' $\mathrm{Hb}>11 \mathrm{~g} / \mathrm{dl}$. 
Table 10: Prevalence of Anemia and Differences in the Hemoglobin Levels of Infants by Age.

\begin{tabular}{|c|c|c|c|}
\hline $\begin{array}{c}\text { Age } \\
\text { (months) }\end{array}$ & Anemic & Normal & Mean \pm SD \\
& $\mathrm{N}(\%)$ & $\mathrm{N}(\%)$ & $\mathrm{Hb} \mathrm{g} / \mathrm{dl}$ \\
\hline $2-5$ & $22(27.5)$ & $58(72.5)$ & $11.4 \pm 1.03$ \\
$6-11$ & $21(26.9)$ & $57(73.1)$ & $11.5 \pm 1.80$ \\
$12-23$ & $20(20.8)$ & $76(79.2)$ & $11.8 \pm 1.12$ \\
\hline Total & $63(24.8)$ & $191(75.2)$ & $11.6 \pm 1.09$ \\
& & & \\
\hline
\end{tabular}


Table 11: Distribution of Educational Levels of the Mothers.

\begin{tabular}{|l|c|c|}
\hline Education & Frequency & Percent \\
& $(\mathrm{N})$ & $(\%)$ \\
\hline Illiterate & 9 & 3.5 \\
Primary & 14 & 5.5 \\
Intermediary & 52 & 20.5 \\
Secondary & 66 & 26.0 \\
Post-Secondary Diploma & 38 & 15.0 \\
University degree & 73 & 28.7 \\
Post-Graduate & 2 & 0.8 \\
\hline Total & 254 & 100.0 \\
\hline
\end{tabular}


awarded a Diploma (the equivalent of a U.S. High School Diploma). The post-secondary education consists of two cycles of two years each. The first cycle leads to a specialist degree (equivalent to a U.S. Associate Degree), and the second cycle leads to an university degree (equivalent of a U. S. Bachelor's Degree).

The distribution of the mothers by occupation status is presented in Table 12 . There were 119 participants $(46.9 \%)$ who did not work outside the home (housewives or retired), thus accounting for of the subjects. Fifty-two (20.5\%) of the mothers were working as clerks, technical staff, or soldiers. There were $56(22 \%)$ participants who were either professionals or businesswomen, and finally, the remaining $27(10.6 \%)$ mothers were students.

The Distribution of the Number of Pregnancies and the Infant Feeding Practices

The distribution of the number of previous pregnancies of the participants is summarized in Table 13. There were $57(29.5 \%)$ mothers who had 1 to 2 pregnancies, 117 mothers (46.1\%) had 3 to 5 pregnancies, and $62(24.6 \%)$ of the mother had six or more pregnancies. On average, the participants had a mean of $3.92 \pm 2.18$ pregnancies. The prevalence of the types of infant feeding practices is presented in Table 14. Twentytwo infants (8.7\%) were breast-fed, 184 infants (72.4\%) were formula-fed, and 48 infants $(18.9 \%)$ were mixed-fed. This showed that the majority of the mothers in this study preferred using infant formula for their infants.

Role of Mothers' Background on BMI and Hemoglobin Levels

We examined the relationships between the environmental conditions of mothers on weight, height, and $\mathrm{Hb}$ levels of infants. It was possible that maternal characteristics, including BMI, Hb levels, type of infant feeding practices, educational levels, 
Table 12: Distribution of Occupations of the Mothers.

\begin{tabular}{|l|c|c|}
\hline Occupation & Frequency & Percent \\
& $(\mathrm{N})$ & $(\%)$ \\
\hline Retired & 1 & 0.4 \\
Professional & 53 & 20.9 \\
Clerk & 5 & 2.0 \\
Technical & 46 & 18.1 \\
Soldier & 1 & 0.4 \\
Student & 27 & 10.6 \\
Businesswoman & 118 & 1.2 \\
Housewife & 254 & 46.5 \\
\hline Total & & 100.0 \\
\hline
\end{tabular}


Table 13: Distribution the Mothers according to the Number of Pregnancies.

\begin{tabular}{|c|c|c|}
\hline Number of pregnancies & $\begin{array}{c}\text { Frequency } \\
(\mathrm{N})\end{array}$ & $\begin{array}{c}\text { Percent } \\
(\%)\end{array}$ \\
\hline 1 & 28 & 11.0 \\
3 & 47 & 18.5 \\
4 & 55 & 21.7 \\
5 & 43 & 16.9 \\
6 & 19 & 7.5 \\
7 & 23 & 9.1 \\
8 & 22 & 8.7 \\
9 & 7 & 2.8 \\
\hline 10 & 6 & 2.4 \\
\hline Total & 4 & 1.6 \\
\hline
\end{tabular}


Table 14: Prevalence of the types of infant feeding practices.

\begin{tabular}{|l|c|c|}
\hline Type of infant feeding & $\begin{array}{c}\text { Frequency } \\
(\mathrm{N})\end{array}$ & $\begin{array}{c}\text { Percent } \\
(\%)\end{array}$ \\
\hline Breast-feeding & 22 & 8.7 \\
Formula-feeding & 184 & 72.4 \\
Mixed-feeding & 48 & 18.9 \\
\hline Total & & \\
\hline
\end{tabular}


occupational status, and numbers of pregnancies could affect the weight and $\mathrm{Hb}$ levels of their infants.

The Effect of the Mothers' Backgrounds on their Infants' Weight and Hb Levels

To evaluate the significance of these factors, an assessment of the mother's BMI was correlated to infant weight and height from 2 through 23 months of age. The correlations between the weight and length of the infants and the mothers' BMI were not significant $(\mathrm{r}=0.08, \mathrm{P}=0.216$ and $\mathrm{r}=0.08, \mathrm{P}=0.185$, respectively). Similarly, the findings did not show a significant correlation between $\mathrm{Hb}$ levels of mothers and $\mathrm{Hb}$ levels of infants $(r=-0.02, P=0.775)$. The mothers' educational levels did not influence their infants' weights $(F=0.70, P=0.495)$ nor their infants' Hb levels $(F=0.69, P=$ 0.504). Similarly, there was no significant differences for weight or $\mathrm{Hb}$ levels of infants by the occupational status of mothers $(\mathrm{F}=0.36, \mathrm{P}=0.782$ and $\mathrm{F}=0.52, \mathrm{P}=0.666$, respectively).

The Effect of the Infant Feeding Practices on the Weight of the Infants

Table 15 shows the relationship between the types of infant feeding practices and the body weight of infants by age grouping. Because the number of exclusively breast-fed infants was small $(n=22)$, we combined the breast-fed group with mixed-fed infants $(n=$ 70 ) in order to be able to make comparisons. There was a significant difference between formula-fed infants and combination breast/mixed fed infants on their weight $(\mathrm{P}<0.001)$. Formula-fed infants were significantly heavier $(9.38 \pm 2.35)$ than breast/mixed-fed infants $(7.98 \pm 1.75)$. When the age groups were broken down into three groups as previously mentioned, the findings showed that there was no significant difference between the mean weights of formula-fed and combination of breast-fed/mixed-fed infants in the 2-5 
month age group $(\mathrm{P}=0.553)$. In the 6-11 month age group, the formula-fed infants had a marginally significant higher mean body weight than the combination of the breast/mixed-fed infants group $(\mathrm{P}=0.092)$. In the $12-23$ month age grouping, there was a significant difference between the formula-fed infants and the combination of breast/mixed-fed infants $(\mathrm{P}=0.012)$. Formula-fed infants had a higher body weight $(11.3$ $\pm 1.56)$ than the combination of breast/mixed-fed infants (10.2 \pm 0.95$)$.

The Effect of the Infant Feeding Practices on the Hb Levels of the Infants

Table 16 shows the relationship between the type of infant feeding practices and the $\mathrm{Hb}$ levels of infants by age grouping. There was a significant difference $(\mathrm{P}=0.006)$ in $\mathrm{Hb}$ levels of formula-fed and the combination of breast/mixed-fed infants when all ages were considered. Formula-fed infants had significantly higher Hb levels $(11.7 \pm 1.12)$ than the combination of breast/mixed-fed infants $(11.2 \pm 0.93)$. When the age groups were broken down, the findings showed that there was no significant difference in Hb levels of formula-fed and the combination of breast-fed and mixed-fed infants in the 2-5 and 6-11 month age groups $(\mathrm{P}=0.191$ and 0.247 , respectively). In the age grouping of $12-23$ months, the findings showed a marginally significant difference between formula-fed infants and the combination of breast-fed/mixed-fed infants $(P=0.098)$, with formula-fed infants having higher Hb levels.

A significant positive correlation was found between age and $\mathrm{Hb}$ levels of infants $(r=0.15, P=0.016)$. Older infants had higher $\mathrm{Hb}$ levels than younger infants (See Figure 1). Also, a significant positive correlation was found between weight and $\mathrm{Hb}$ levels of 
Table 15: Relationship Between the Types of Infant Feeding Practices and the Body Weight of Infants by Age Grouping ${ }^{1,2}$

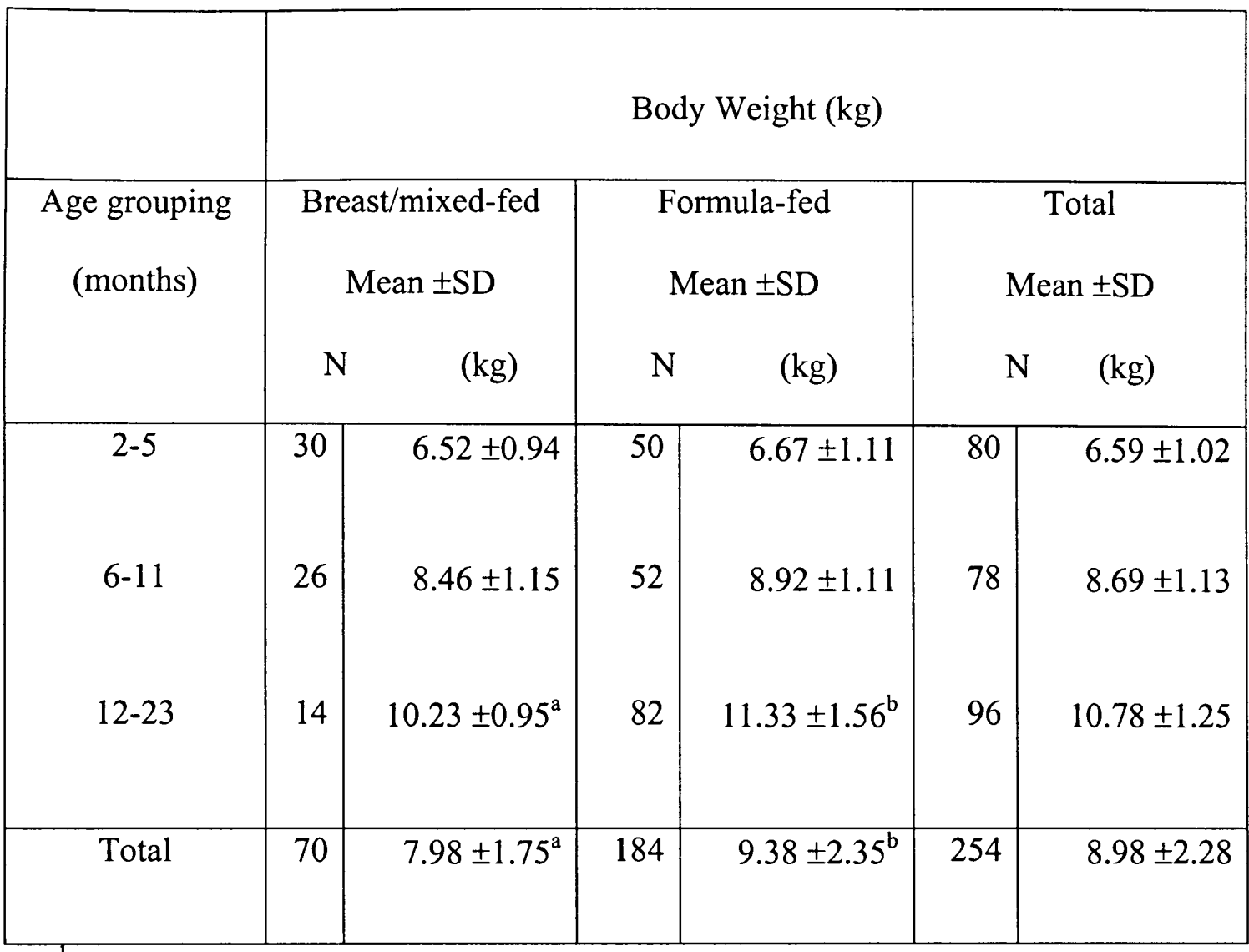

${ }^{\mathrm{I}}$ Breast and mixed fed groups were combined for this analysis.

${ }^{2}$ Means with different superscripts within a row are significantly different at $\mathrm{P}<0.05$. 
Table 16: Relationship Between the Types of Infant Feeding Practices and the Hb Levels of Infants by Age Grouping ${ }^{1}$

\begin{tabular}{|c|c|c|c|c|c|c|}
\hline & \multicolumn{5}{|c|}{ Hemoglobin Level (g/dl) } \\
\hline Age & \multicolumn{2}{|c|}{ Breast/mixed-fed } & \multicolumn{2}{c|}{ Formula-fed } & \multicolumn{2}{c|}{ Total } \\
grouping & \multicolumn{2}{|c|}{ Mean \pm SD } & \multicolumn{2}{|c|}{ Mean \pm SD } & \multicolumn{2}{c|}{ Mean \pm SD } \\
(months) & $\mathrm{N}$ & $(\mathrm{g} / \mathrm{dl})$ & $\mathrm{N}$ & $(\mathrm{g} / \mathrm{dl})$ & $\mathrm{N} / \mathrm{dl})$ \\
\hline $2-5$ & 30 & $11.22 \pm 0.93$ & 50 & $11.54 \pm 1.07$ & 80 & $11.43 \pm 1.03$ \\
& & & & & & \\
& 26 & $11.29 \pm 0.99$ & 52 & $11.60 \pm 1.11$ & 78 & $11.50 \pm 1.08$ \\
$12-23$ & 14 & $11.29 \pm 0.89$ & 82 & $11.83 \pm 1.14$ & 96 & $11.76 \pm 1.11$ \\
& & & & & & \\
\hline Total & 70 & $11.26 \pm 0.93^{\mathrm{a}}$ & 184 & $11.70 \pm 1.11^{\mathrm{b}}$ & 254 & $11.57 \pm 1.08$ \\
& & & & & & \\
\hline
\end{tabular}

${ }^{1}$ Breast-fed and mixed-fed groups were combined for this analysis.

${ }^{2}$ Means with different superscripts within a row are significantly different at $\mathrm{P}<0.05$. 
Figure 1: Relationship Between the Age and Hemoglobin Levels of Infants.

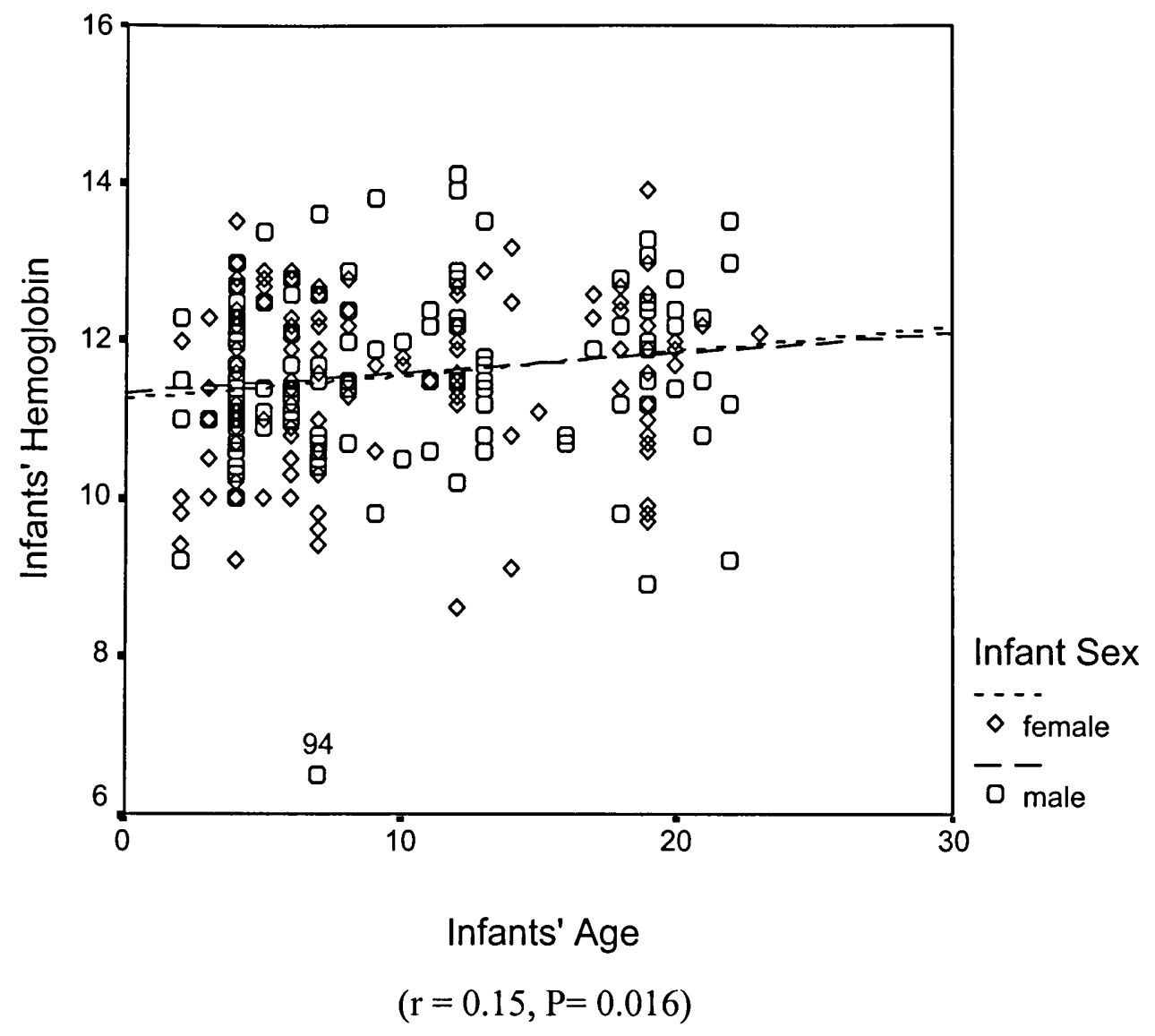


infants $(\mathrm{r}=0.24, \mathrm{P}<0.001)$. The heavier the infant, correspondingly, the Hb level was higher (Figure 2).

The Effect of Education and Occupation of the Mothers on their BMI and $\mathrm{Hb}$

Tables 17 and 18 show the effect of educational level and occupational status of the mothers on their BMI, $\mathrm{Hb}$ level, and the number of pregnancies. There was no evidence to indicate a difference among educational levels on the mothers' $\mathrm{BMI}(\mathrm{F}=$ $1.22, \mathrm{P}=0.296$ ). Similarly, the effect of occupation on the BMI of mothers was not significant $(F=0.86, P=0.460)$. There was a marginally significant difference in the mean $\mathrm{Hb}$ by educational levels of the mothers $(\mathrm{F}=2.99, \mathrm{P}=0.052)$. Additionally, there was a significant difference in the mean $\mathrm{Hb}$ levels of mothers among the occupational groups $(F=2.78, P=0.042)$. The prevalence of anemia among housewives/retired mothers and student mothers was $28.6 \%$ and $29.6 \%$, respectively. This rate dropped down to $23.1 \%$ and $16.1 \%$ among clerks/technical staff, and professionals/ businesswomen, respectively. The mean $\mathrm{Hb}$ level of professionals/ businesswomen was significantly $(\mathrm{P}=0.031)$ higher than the mean $\mathrm{Hb}$ of housewives/retired mothers, 13.3 \pm 1.42 and $12.7 \pm 1.21$, respectively.

Analysis of the number of pregnancies by educational level showed that there was a significant difference among groups $(\mathrm{F}=8.22, \mathrm{P}<0.001)$. Mothers with minimal or no education had the highest number of pregnancies ( $4.7 \pm 2.4$ pregnancies $)$ compared to moderately and highly educated mothers $(3.8 \pm 2.1$ and $3.3 \pm 1.9$ pregnancies, respectively). A further analysis of the number of pregnancies by occupation showed a significant difference among groups $(\mathrm{F}=3.67, \mathrm{P}=0.013)$. Non-working mothers 
Figure 2: Relationship Between Body Weight and Hemoglobin Levels of Infants.

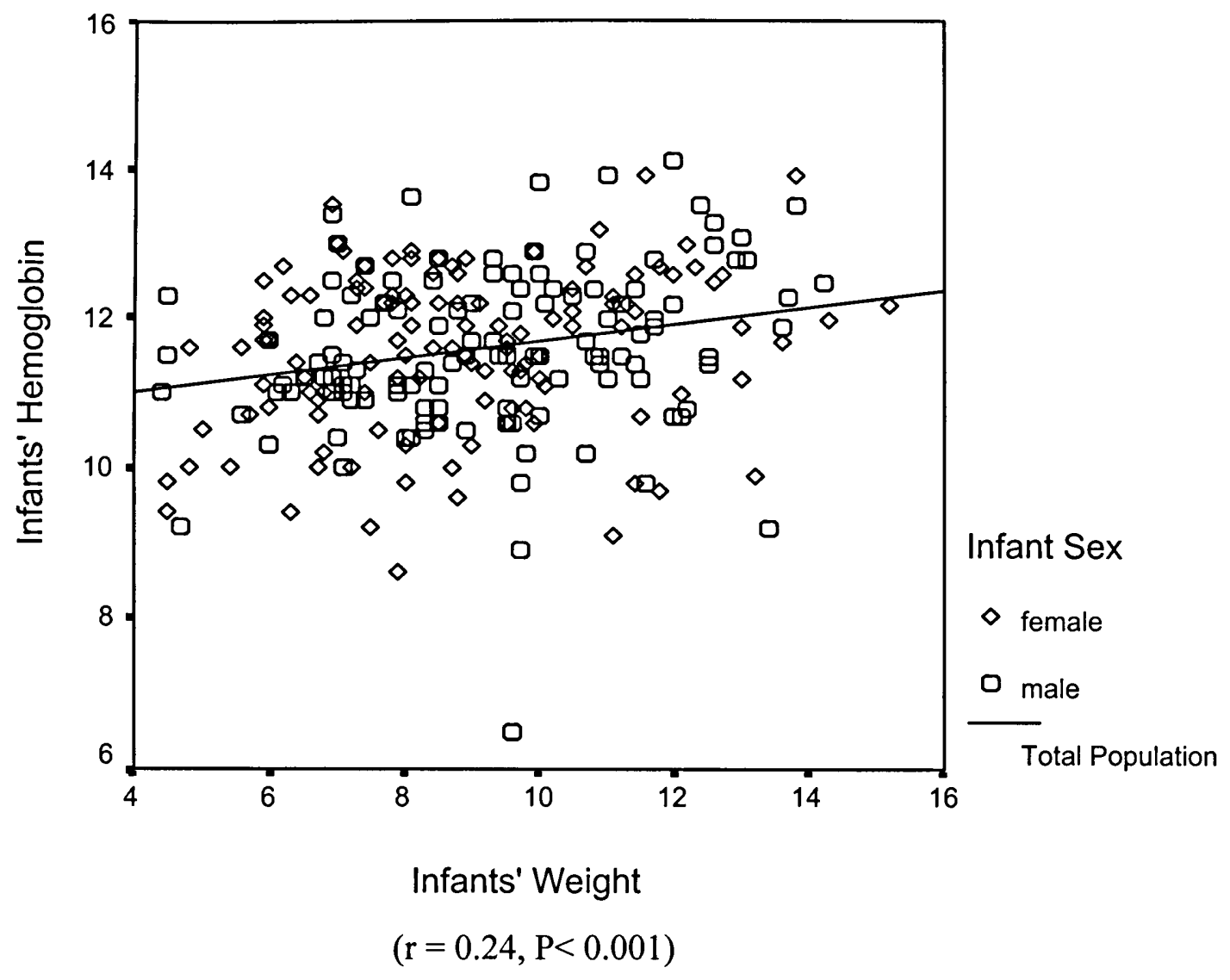


Table 17: Effect of Educational Level of the Mothers on their BMI, Hb, and Number of Pregnancies ${ }^{1}$

\begin{tabular}{|l|c|c|c|c|}
\hline Education & $\mathrm{N}$ & BMI & Hemoglobin & Number of \\
& & Mean \pm SD & Mean \pm SD & pregnancies \\
Mean \pm SD
\end{tabular}

${ }^{\mathrm{T}}$ Means with different superscripts in a column are significantly different at $\mathrm{P}<0.05$. 
Table 18: Effect of Occupational Status of Mothers on their BMI, Hb, and Number of Pregnancies ${ }^{1}$

\begin{tabular}{|l|c|c|c|c|}
\hline \multicolumn{1}{|c|}{ Occupation } & $\mathrm{N}$ & BMI & Hemoglobin & Number of \\
& & Mean $( \pm \mathrm{SD})$ & Mean $( \pm \mathrm{SD})$ & $\begin{array}{c}\text { pregnancies } \\
\text { Mean }( \pm \mathrm{SD})\end{array}$ \\
\hline Housewife/retired & 119 & $29.3 \pm 4.8$ & $12.7 \pm 1.2^{\mathrm{a}}$ & $4.4 \pm 2.4$ \\
Clerk/technician/soldier & 52 & $30.3 \pm 5.0$ & $13.0 \pm 1.5^{\mathrm{ab}}$ & $3.5 \pm 1.8$ \\
Professional/businesswoman & 56 & $29.4 \pm 4.9$ & $13.3 \pm 1.4^{\mathrm{b}}$ & $3.6 \pm 2.0$ \\
\hline Student & & & & \\
\hline Total & 27 & $28.6 \pm 5.0$ & $13.1 \pm 1.5^{\mathrm{ab}}$ & $3.2 \pm 1.9$ \\
\hline
\end{tabular}

${ }^{1}$ Means with different superscripts in a column are significantly different at $\mathrm{P}<0.05$. 
(housewives and the retired mothers) had the highest number of pregnancies of the groups. But when Tukey's post hoc test was used for further comparisons, the findings showed only a marginally significant difference in number of pregnancies of nonworking mothers compared to clerk/technician/soldier and student mothers $(\mathrm{P}=0.072$ and $\mathrm{P}=0.067$, respectively).

The Effect of the Education and Occupation on the Type of Infant Feeding

The relationships between type of infant feeding practice and educational level, and occupation of mothers are presented in Tables 19 and 20, respectively. An analysis of the type of infant feeding practice by educational level showed that there was a marginally significant difference $(P=0.072)$. Twenty-nine percent of the mothers with low educational levels preferred mixed-feeding compared to only $16 \%$ of the mothers with moderate educational levels and $12 \%$ of the highly educated mothers. Further analysis showed that the type of infant feeding practice did not differ by occupational status.

The Effect of the Number of Pregnancies on the BMI and $\mathrm{Hb}$ of Mothers

Figure 3 shows the relationship between the number of pregnancies and the BMI of mothers. The findings showed that there was a significant correlation between the number of pregnancies and the BMI of mothers $(r=0.199, \mathrm{P}=0.001)$. Mothers who experienced a high number of pregnancies had a higher BMI than those who had experienced only fewer pregnancies. In contrast, the number of pregnancies and $\mathrm{Hb}$ levels of mothers were not significantly correlated $(r=-0.09, P=0.148)$. Furthermore, the mean number of pregnancies of mothers who breast/mixed-fed their infants $(4.77 \pm 2.34)$ 
Table 19: Relationship Between Infant Feeding Practices and Educational Levels of Mothers.

\begin{tabular}{|l|c|c|c|c|}
\hline & \multicolumn{3}{|c|}{ Type of infant feeding } \\
\hline Education & Breast-fed & Formula-fed & Mixed-fed & Total \\
& N (\%) & N (\%) & N (\%) & N (\%) \\
\hline Illiterate/primary/intermediary & $7(9.3)$ & $46(61.3)$ & $22(29.3)$ & $75(100.0)$ \\
\hline Secondary/post-secondary & $9(8.7)$ & $78(75.0)$ & $17(16.3)$ & $104(100.0)$ \\
\hline & & & & \\
University/post-graduate & $6(8.0)$ & $60(80.0)$ & $9(12.0)$ & $75(100.0)$ \\
\hline Total & $22(8.7)$ & $184(72.4)$ & $48(18.9)$ & $254(100.0)$ \\
\hline
\end{tabular}


Table 20: Relationship Between Infant Feeding Practices and Occupational Status of Mothers.

\begin{tabular}{|c|c|c|c|c|}
\hline & \multicolumn{4}{|c|}{ Type of infant feeding } \\
\hline Occupation & $\begin{array}{c}\text { Breast-fed } \\
\text { N (\%) }\end{array}$ & $\begin{array}{c}\text { Formula-fed } \\
\qquad \mathrm{N}(\%)\end{array}$ & $\begin{array}{c}\text { Mixed-fed } \\
\text { N (\%) }\end{array}$ & $\begin{array}{l}\text { Total } \\
\mathrm{N}(\%)\end{array}$ \\
\hline Housewife/retired & $11(9.3)$ & $80(67.2)$ & $28(23.5)$ & $119(100.0)$ \\
\hline Clerk/technician/soldier & $2(3.8)$ & $43(82.7)$ & $17(13.5)$ & $52(100.0)$ \\
\hline Profession/businesswoman & $5(8.9)$ & $42(75.0)$ & $9(16.1)$ & $56(100.0)$ \\
\hline Student & $4(14.8)$ & $19(70.4)$ & $4(14.8)$ & $27(100.0)$ \\
\hline Total & $22(8.7)$ & $184(72.4)$ & $48(18.9)$ & $254(100.0)$ \\
\hline
\end{tabular}


Figure 3: Relationship Between Numbers of Pregnancies and BMI of Mothers.

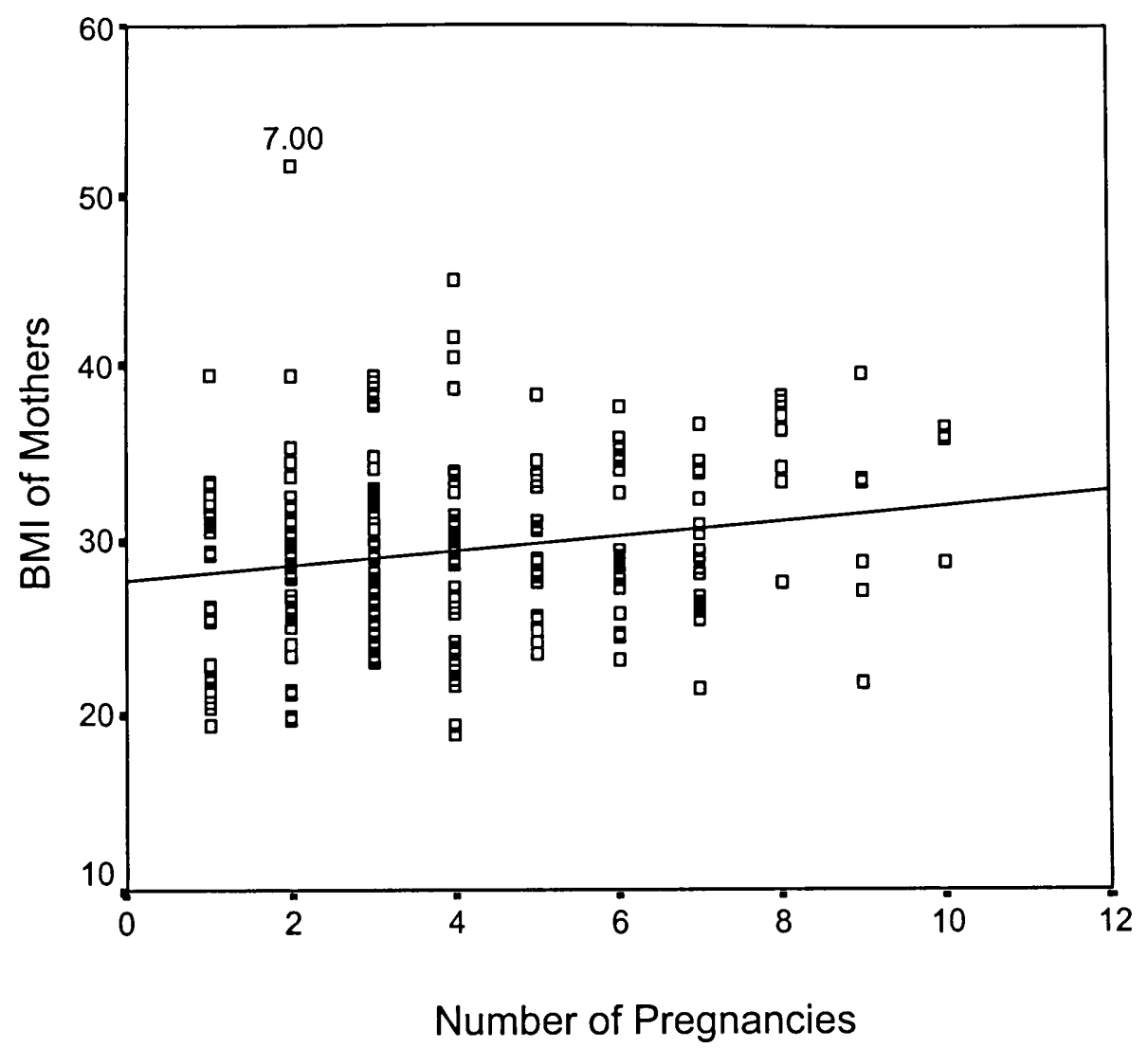

$$
(r=0.199, P=0.001)
$$


was significantly higher $(\mathrm{P}<0.001)$ than the mean number of pregnancies of those mothers who formula-fed their infants $(3.60 \pm 2.04)$. 


\section{DISCUSSION}

The problems of obesity and anemia are very complex. It is very difficult to identify the exact factor(s) that may lead to obesity and anemia. The present study provided an opportunity for an extensive evaluation of the effect of independent factors (BMI, $\mathrm{Hb}$, education, occupation, and number of pregnancies), which may impact Kuwaiti mothers' weight and hemoglobin levels, as well as the weight and hemoglobin levels of their infants.

The findings of our study indicated that the body weight and height of Kuwaiti infants were not correlated with the BMI of their mothers, which was not consistent with previous studies (Roberts et al., 1988; Whitaker et al., 2000). These previous studies found that genetic factors were important contributors to infants' weight and height; in other words, infants of overweight and tall mothers tend to be overweight and tall. However, this study found that maternal anthropometry (heights and weights) was not correlated with infant weights or heights and did not support the hypothesis that heavier and taller infants have mothers who were heavier and taller. Therefore, the hypothesis that the incidence of overweight among infants would be positively correlated with the BMI of their mothers was not confirmed.

This study showed that the prevalence of overweight and obesity among mothers was high ( $44.9 \%$ and $37.8 \%$, respectively) and consistent with the previous study by AlIsa (1995). The high incidence of overweight and obesity may be due to the lifestyles in Kuwait, which include a high consumption of dietary fat and a low level of physical 
activity (Al-Awadi \& Amine, 1989). Al-Awadi and Amine (1990) found that the presence of housekeepers resulted in a reduction in physical activity, which might have been otherwise exerted by the mothers at home. This might be partly responsible for the higher prevalence of overweight and obesity among Kuwaiti mothers. It should be noted that these mothers just had babies and many may not have lost the weight they gained during pregnancy.

It is useful to study the factors associated with childhood obesity in different populations, since these factors vary from one population to another. Using the National Center for Health Statistics (NCHS) has served a useful purpose by allowing global comparisons of the nutritional status of various populations. Also, it has been widely used in growth charts for assessing the growth of individual children. The growth pattern of Kuwaiti infants in this study was compared to the American infants using the NCHS reference. Kuwaiti infants had a prevalence of underweight of $4.3 \%$, and overweight of $8.3 \%$; while American infants had a prevalence of underweight of $3.1 \%$, and overweight of $11.3 \%$ (DHHS, 1997). The prevalence of short stature among Kuwaiti infants was $3.1 \%$, while the prevalence of short stature among American infants was $9.7 \%$. These findings indicated that the mean weight-for-age of American infants was above the mean weight-for-age of Kuwaiti infants and the prevalence of short stature among American infants was higher than for Kuwaiti infants. Conversely, Al-Isa and Mousa (1998) compared Kuwaiti children aged 0-5 years with the NCHS/CDC reference population, and found that the rate of obesity among Kuwaiti children was $8.2 \%$ and they were slightly heavier than the American children. 
It has commonly been stated that iron deficiency anemia is a common public health problem in Arabian Gulf States, especially Kuwait (Jackson \& Al-Mousa, 1999). Review of the literature revealed that children are the most affected group. We found a high prevalence of anemia among Kuwaiti infants aged 2 to 23 months; one of four infants in our study was considered anemic (24.8\%) based on the Word Health Organization (WHO) standards $(\mathrm{Hb}<11 \mathrm{~g} / \mathrm{dl})$. Although our rate of anemia among infants is less than that reported by Najwa and Himadri (2000) $(36.7 \%$ among Kuwaiti children aged six to 144 months), it is still considered to be high. An $18.5 \%$ prevalence of anemia was found among Kuwaiti mothers $(\mathrm{Hb}<12 \mathrm{~g} / \mathrm{dl})$, which is comparable to that reported by Al-Awadi and Amine in 1987 among Kuwaiti adult females (17.9\%). Our findings indicated that the $\mathrm{Hb}$ levels of mothers were not related to the $\mathrm{Hb}$ levels of their infants. Consequently, our hypothesis that the incidence of anemia among infants would be positively correlated with the Hb levels of their mothers was not shown.

The prevalence of anemia among Kuwaiti infants in this study was also compared to American infants using the World Health Organization (WHO) standards. The prevalence of anemia among American infants was $18.4 \%$ (DHHS, 1997). This indicated a significantly higher prevalence of anemia among Kuwaiti infants than their counterparts in the USA $(\mathrm{P}=0.004)$. Our findings and others indicated that the prevalence of anemia among Kuwaiti infants has remained alarmingly high over the last three decades and therefore, a diet of iron-fortified foods (formula) should be made available to alleviate this problem. Iron-deficiency anemia may result in developmental delays and behavioral disturbances (e.g., decreased motor activity, social interaction, and attention to tasks). These developmental delays may persist past school age (i.e., 5 years) if the iron 
deficiency is not fully reversed (Idjradinata \& Pollitt, 1993). Jackson and Al-Mousa (1999) found that the incidence of anemia among the Kuwaiti population was due to whether or not the Kuwaiti dishes are being adequately supplemented with iron-rich foods and to the increasing consumption of beverages such as tea and coffee, which limit the bioavailability of ingested iron from foods.

The significant role of the feeding intensity in relationship to infant growth may be a reflection of the health and well-being of the infants. In agreement with previous studies by Agostoni et al. (1999) and Dewey et al. (1993), we found that formula-fed infants had a significantly higher body weight $(\mathrm{P}<0.001)$ than the combination of breastfed and mixed-fed infants when all ages were considered. When the age groups were broken down, we found no differences in body weight of infants within the 2-5 month age grouping between formula-feeding and combination feeding. In the 6-11 month age grouping, a combination of breast-fed and mix-fed infants showed a relatively lower body weight than the formula-fed infants. In the age grouping of 12-23 months, the findings indicated that the formula-fed infants had a very significant difference $(\mathrm{P}=0.0012)$ in higher body weight than the infants with combination feeding. It should be noted that the formula-fed group may have affected the finding in the 12-23 month group due to the high numbers (82) as compared to the smaller group of combination of breast-fed and mixed-fed (14) infants. A combination of breast-feeding and mix-feeding was associated with a lower weight-for-age and weight-for-length than formula-feeding. Consequently, our hypothesis that the breast-fed infants would have a lower body weight than infants who are formula-fed was accepted. 
Further analysis of combination-fed infants (breast-fed and mixed-fed infants) as compared to the predominantly formula-fed infants showed a significant difference in the $\mathrm{Hb}$ levels when all ages were considered $(\mathrm{P}=0.006)$, which was consistent with a study by Calvo, Galindo, and Aspres (1992). Our findings validated our hypothesis that the breastfed infants would have lower $\mathrm{Hb}$ levels than infants who are formula-fed. When the age groups were broken down into three groups as previously mentioned, we found only one marginally significant difference in $\mathrm{Hb}$ levels at the 12-23 month age group, where formula-fed infants had higher $\mathrm{Hb}$ levels than the combination-fed infants. Thus, these findings indicated that the prevalence of anemia may be more common in breast-fed infants, suggesting that supplementation with iron fortified foods after six months of age should be emphasized.

Our findings showed that the prevalence of anemia is significantly higher among younger infants than older infants $(\mathrm{P}=0.016)$, which is consistent with a previous study by Najwa and Himadri (2000). In terms of the relationship between body weight and $\mathrm{Hb}$ of infants, we found sufficient evidence to indicate a correlation between body weight and $\mathrm{Hb}$ levels of infants $(\mathrm{P}<0.001)$. Infants with a lower body weight had a higher prevalence of anemia than those with a higher body weight.

We used independent factors such as the educational levels and occupation status of mothers to analyze their effects on the BMI and $\mathrm{Hb}$ levels of the mothers and infants. Our study did not support the hypothesis that the educational levels of mothers would be inversely related to their BMI and to the weight and height of their infants. Previous studies by Moussa (1994) and Amy et al. (2000) showed that the incidence of obesity (body mass index: $\geq 30 \mathrm{~kg} / \mathrm{m}^{2}$ ) was more common in the low education group of mothers 
( $30 \%$ vs. $17 \%$ ), and their children tended to be more overweight (weight-for-height percentile: $\geq 90$ th; $19 \%$ vs. $14 \%$ ). In contrast with previous reports by Al-Awadi and Amine (1989) and Moussa (1999), we found that mothers' occupation status was not related to their BMIs or to the weights of their infants. We hypothesized that there was an inverse relationship between mothers' educational levels and occupational status and their BMI and their infants' weight, but our findings did not support this hypothesis.

The association between the mothers' occupations and the Hb levels of mothers and infants were evaluated in this study. We found that mothers' occupations were positively correlated only with the changes in the $\mathrm{Hb}$ levels of mothers $(\mathrm{P}=0.042)$, which was consistent with the results reported by Al-Awadi and Amine (1987). These findings indicated that anemia was more common among housewives than those who are professionals. Thus, our findings support our hypothesis that there would be a positive relationship between the mothers' occupational status and their $\mathrm{Hb}$ levels. However, the mothers' occupation did not have a significant relationship with the Hb levels of their infants. The findings also indicated that the prevalence of anemia was not significantly different in mothers from different educational levels, and were consistent with Al-Awadi and Amine (1987). Thus, the hypothesis that there would be a positive relationship between the mothers' education and their $\mathrm{Hb}$ levels and $\mathrm{Hb}$ levels of their infants was not confirmed.

Furthermore, our findings indicated that mothers with minimal or no education had a significantly higher number of pregnancies $(\mathrm{P}<0.001)$ compared to moderately and highly educated mothers. Also, the number of pregnancies by occupation was analyzed 
and showed a significant difference between groups $(P=0.013)$. Non-working mothers (housewives and the retired mother) had the highest number of pregnancies of all other groups. All these relationships were consistent with the findings of Al-Awadi and Amine (1989). On average, Kuwaiti mothers had a mean of 3.92 pregnancies. This high mean may be due to the fact that the Government of Kuwait encourages families to have more children through incentives such as increasing the household income monthly as much as 50 Kuwaiti Dinars (equivalent to $\$ 180.00$ US) for each additional child.

In addition, this study provided an analysis of the determinants of types of infant feeding practices. The educational levels of the mothers and their occupational status have been previously found to be the two most important independent factors that influence the decision to breastfeed. However, the interaction between these factors may differ in various populations (Karinij, Shiono, \& Rhoads, 1988). Interestingly, we found only a marginally significant relationship between educational levels of mothers and types of infant feeding practices. Mothers with little education preferred using mixfeeding (29\%) compared to those who were moderately and highly educated $(16 \%$ and $12 \%$, respectively). In contrast with our findings, Al-Awadi and Amine (1989) found that the mothers' educational levels significantly modified the infant feeding practices. Illiterate mothers were more likely to breast-feed their infants $(38.4 \%)$ than mothers who had university degrees (26.1\%) (Al-Awadi and Amine); conversely, mothers with high educational levels in the US are more likely to breast-feed their infants. Also, the occupational status of mothers did not influence the type of infant feeding practice. We have found in this study that the incidence of breast-feeding (8.7\%) was comparable to that found in a previous study by Mostafa (1979). The low incidence of breast-feeding 
may be due to the presence of expatriate housekeepers who have substituted formulafeeding in place of the mother's breast-feeding (Al-Awadi \& Amine, 1990). This may reflect the importance of family psychosocial support to breast-feeding success.

Our findings indicated significant relationships between the number of pregnancies and the BMI of mothers. Mothers who had high number of pregnancies had a higher $\mathrm{BMI}$ than those who had fewer pregnancies $(\mathrm{P}=0.001)$. The present research validated our hypothesis that the incidence of overweight or obesity was more prevalent among multiparous mothers. However, we were unable to establish a relationship between the number of pregnancies and the $\mathrm{Hb}$ levels of mothers. The hypothesis that the incidence of anemia would be more prevalent among multiparous mothers was not demonstrated.

In conclusion, the small sample of the breast-fed infants used in this study was a limitation. Moreover, the sample was not selected randomly (convenience sample) and therefore, it might not represent the overall Kuwaiti population. Studying obesity in an early age is important since identification of children who may become obese adults can facilitate early intervention and avoidance of the morbidity and mortality associated with adult obesity. Although the weight and height of the infants in this study appeared to be within the expectations for their age group, about $8.3 \%$ of these infants were overweight; $4.3 \%$ were underweight; and $3.1 \%$ were of short stature. Our findings reinforce the recommendation that breast-fed infants should be given supplemental iron from the sixth month of life, when iron reserves at birth are likely to be depleted.

The present study suggests that future research of weight should include measures of other infant and family parameters such as physical activity, eating habits, and health 
issues along with genetic factors. Also, future studies are needed to test whether infant formulas with iron are adequate to preserve iron stores beyond six months of age. The high prevalence of anemia among infants and its relationship with adverse developmental outcomes suggests that prevention of anemia should be emphasized, rather than treatment. This study suggests that comprehensive programs for the prevention and control of obesity and anemia in Kuwait are needed and should be a priority on the national nutrition and health agenda at an early age, which also takes into account the health and behavior of both mothers and infants. 


\section{LIST OF REFERENCES}

Agostoni, C., Grandi, F., Giannì, L., Silano, M., Torcoletti, M., Giovannini, M., \& Riva, E. (1999). Growth patterns of breast-fed and formula fed infants in the first 12 months of life: an Italian study. Archives of Disease in Childhood, 81, 395-399.

Al-Awadi, F., \& Amine, E.K. (1989). Overweight and obesity in Kuwait. Journal of the Royal Society and Health, 109 (5), 175-177.

Al-Awadi, F., \& Amine, E.K. (1992). The impact of family income on meal patterns in Kuwait. Publication Report by The Department of Food and Nutrition Administration, Kuwait: Ministry of Health.

Al-Awadi, F., Amine, E.K., \& Goulam, Z. (1995). Assessment of the nutritional status of vulnerable groups in Kuwait. Publication Report by Food and Nutrition Administration, Kuwait: Ministry of Health.

Al-Bustan, M., \& Kohli, B. (1988). Socio-economic and demographic factors influencing breast-feeding among Kuwaiti women. Genus, 44, 265-276.

Al-Harbee, N. (1994). An assessment of growth and development of toddlers in Kuwait. Kuwait Medical Association, 45, 260-265.

Al-Isa, A. (1995). Prevalence of obesity among adult Kuwaitis: a cross-sectional study. International Journal of Obesity, 19, 431-433.

Al-Isa, A.N., \& Moussa, M.A. (1998). Obesity among Kuwaiti pre-school children aged 0-5 years: Prevalence and comparison with the NCHS/CDC reference population. Nutrition and Health, 12 (4), 235-46.

Al-Isa, A.N., \& Moussa, M.A. (2000). Nutritional status of Kuwaiti elementary school children aged 6-10 years: Comparison with the NCHS/CDC reference population. International Journal of Food Sciences and Nutrition, 51(4), 221-228.

Al-Shawi, A. (1985). The dietary patterns and food habits of Kuwaiti housewives of three educational levels. The Educational Journal, 2, 9-11, Kuwait University Press.

American Academy of Pediatrics (1978). A commentary in celebration of the International Year of the Child, 1979. Pediatrics, 62, 591-601. 
Amine, E., \& Al-Awadi, F. (1986). Study of the nutritional status of school students at the intermediate level in Kuwait. Publication Report by Department of Food and Nutrition Administration. Kuwait: Ministry of Health of Kuwait.

Amine, E., \& Al-Awadi, F. (1987). Anemia among adult females in Kuwait. Publication Report by Department of Food and Nutrition Administration. Kuwait: Ministry of Health of Kuwait.

Amine, E., \& Al-Awadi, F. (1989). Impact of mother's education on infants feeding patterns and weaning practices in Kuwait. Ecology of Food and Nutrition, 24, 29-36.

Amine, E., \& Al-Awadi, F. (1990). Expatriate maids and food patterns in Kuwait. Journal of the Royal Society of Health, 110 (4),138-140.

Amine, E., \& Al-Awadi, F. (1992). Family income and meal patterns in Kuwait. Publication Report by Department of Food and Nutrition Administration. Kuwait: Ministry of Health of Kuwait.

Amy, E., Baughcum, A., Chamberlin, M., Deeks, P., \& Whitaker, R. (2000). Maternal perceptions of overweight preschool children. Pediatrics, 106, 1380-1386.

Bundred, P., Kitchiner, D., \& Buchan, I. (2001). Prevalence of overweight and obese children between 1989 and 1998: population based series of cross sectional studies. British Medical Journal, 322, 326-328.

Calvo, E.B., Galindo, A.C., \& Aspres, N.B. (1992). Iron status in exclusively breast-fed infants. Pediatrics, 90, 375-379.

Centers for Disease Control and Prevention. (1998). Pediatric Nutrition Surveillance, 1997 Full Report. Atlanta: U.S. Department of Health and Human Services.

Centers for Disease Control and Prevention. (2000). CDC Growth Charts: Unites States. Atlanta: U.S. Department of Health and Human Services. Advanced Data, 314, 1-28.

Dallman, R., Siimes, A., \& Stekel, A. (1980). Iron deficiency in infancy and childhood. American Journal of Clinical Nutrition, 33, 86-118.

DeMaeyer, E.M., \& Adiels-Tegman, M. (1985). The prevalence of anemia in the world. World Health Statistics, 38, 302-316.

Dewey, K.G., Heinig, M.J., Nommsen, L.A., Peerson, J.M., \& Lönnerdal, B. (1993). Breast-fed infants are leaner than formula-fed infants at one year of age: The DARLING study. American Journal of Clinical Nutrition, 57, 140-144. 
Dewey, K.G., Peerson, J.M., \& Brown, K.H. (1995). Growth of breast-fed infants deviates from current reference data: A pooled analysis of US, Canadian, and European data sets. Pediatrics, 96, 495-503.

Dibley, M.J., Goldsby, J.B., Staehling, N.W., \& Trowbridge, F.L. (1987). Development of normalized curves for the international growth reference: historical and technical considerations. American Journal of Clinical Nutrition, 46, 736-748.

Eid, N., Al-Hooti, S., \& Khalafawi, M. (1986). Nutritional anthropometry of school children in Kuwait. Nutrition Reports International, 33, 253.

Eid, N., Al-Hooti, S., Bourisly, N., \& Khalafawi, M. (1984). Nutritional anthropometry of school children in Kuwait. Department of Biotechnology. Publication Report by Kuwait Institute for Scientific Research. Kuwait.

Hassan, K., Sullivan, M., Yip, R., \& Woodruff, A. (1997). Factors associated with anemia in refugee children. Journal of Nutrition, 127, 2194-2198.

Healthy People 2000 (1992). National health promotion and disease prevention objectives. (DHHS Publication No. PHS 91-50212/G). Washington, DC: US Dept of Health and Human Services.

Idjradinata, P., \& Pollitt, E. (1993). Reversal of developmental delays in irondeficient anemic infants treated with iron. Lancet, 341,8836, 1-4.

Jackson, R., \& Al-Mousa, Z. (2000). Iron deficiency is a more important cause of anemia than hemoglobinopathies in Kuwaiti adolescent girls. Journal of Nutrition, $\underline{130,1212-1216 .}$

Jackson, R., Al-Mousa, Z., Mughal, H., \& Nkansa, D. (1999). The prevalence and etiology of anemia in Kuwaiti preschoolers and adolescents. The Kuwait Medical Journal, 31, 33-39.

Johnson, S.L., \& Birch, L.L. (1994). Parents' and children's adiposity and eating style. Pediatrics, 94, 653-661.

Kuczmarski, R.J., Flegal, K.M., Campbell, S.M., \& Johnson, C.L. (1994). Increasing prevalence of overweight among US adults: The National Health and Nutrition Examination Surveys, 1960 to 1991. Journal of the American Medical Association, 272, 205-211.

Lissau, I., \& Sorensen, T. (1994). Parental neglect during childhood and increased risk of obesity in young adulthood. Lancet, 343, 324-327.

Lozoff, B., Jimenez, E., \& Wolf, A.W. (1991). Long-term developmental outcome of infants with iron-deficiency. New England Journal of Medicine, 325 , $687-694$. 
Martorell, R., Kettel-Khan, L., Hughes, ML., \& Grummer-Strawn, L.M. (2000). Overweight and obesity in preschool children from developing countries.

International Journal of Obesity, 24, 959-967.

Ministry of Health. Kuwait: Kuwait Health Survey. 1985.

Ministry of Information. (1996). Kuwait Facts and Figures International Media $\left(5^{\text {th }}\right.$ Edition), Information Publication Administration.

Mira, M., Alperstein, G., Karr, M., Ranmuthugala, G., Causer, J., Niec, A., \& Lilburne, M. (1996). Heme iron intake in 12-36 month old children depleted in iron: Case-control study. British Medical Journal, 312, 881-883.

Mostafa, S., \& Nuwayhed, H. (1979). Growth patterns of Kuwaiti children from birth to 60 months. Publication Report by Department of Public Health and Planning, Kuwait: Ministry of Public Health.

Moussa, M. (1994). Factors associated with obesity in school children. Kuwait Medical Association, 45, 96-199.

Moussa, M., Shaltout, A., Nkansa-Dwamena, D., Mourad, M., Alsheikh, N., Agha, N., \& Galal, D. (1999). Factors associated with obesity in Kuwaiti children. European Journal of Epidemiology, 15(1), 41-49.

Najwa, A., Himadri, D., Thomas, M., \& Adekunle, A. (2000). Prevalence and etiology of anemia to a general hospital in Kuwait. The Kuwait Medical Journal, (2) $\underline{32}, 154-158$.

Nieto, F.J., Szklo, M., \& Comstock, G.W. (1992). Childhood weight and growth rate as predictors of adult mortality. American Journal of Epidemiology, 136, 201213.

Palti, H., Adler, B., \& Rashef, A. (1977). A semilongitudinal study of food intake, anemia rate and body measurements of 6 to 24-months-old children in a Jerusalem community. American Journal of Clinical Nutrition, 30, 268-274.

Power, C., Lake, J.K., \& Cole, T.J. (1997). Measurement and long-term health risks of child and adolescent fatness. International Journal of Obesity and Related Metabolic Disorders, 21, 507-526.

Richard, S., \& Knight, J. (1999). Influence of the home environment on the development of obesity in children. Pediatrics, 103, 85-89.

Roberts, S., Savage, J., Coward, W., Chew, B., \& Lucas, A. (1988). Energy expenditure and intakes of infants born to lean and overweight mothers. New England Journal of Medicine, 318, 461-466.

Rolland-Cachera, M.F., Deheeger, M., Bellisle, F., Sempé, M., Guilloud-Bataille, M., \& Patois, E. (1984). Adiposity rebound in children: A simple indicator for predicting obesity. American Journal of Clinical Nutrition, 39, 129-135. 
Ruther, N.M., \& Richman, C.L. (1993). The relationship between mothers' eating restraint and their children's attitudes and behaviors. Bulletin Psychonomic Society, $\underline{31,217-236 .}$

Sadowitz, P.D., \& Oski, F.A. (1983). Iron status and infant feeding practices in an urban ambulatory centre. Pediatrics, 72, 33-36.

Scrimshaw, N.W. (1984). Functional consequences of iron-deficiency. Journal of Nutrition Science and Vitaminology, 30, 47-63.

SPSS for Windows 10.0.7 [Computer Software]. (2000). Chicago, IL: SPSS, Inc.

Stunkard, A., Berkowitz, R., Stallings, V., \& Schoeller, D. (1999). Energy intake, not energy output, is a determinant of body size in infants. American Journal of Clinical Nutrition, 69, 524-530.

Villalpando, S., \& López-Alarcón, M. (2000). Growth faltering is prevented by breast-feeding in underprivileged infants from Mexico City. Journal of Nutrition, 130 , 546-552.

Waterlow, J., Ashworth, A., \& Griffiths, M. (1980). Faltering in infant growth in less-developed countries. Lancet, 2, 1176-1183.

Whitaker, C., Deeks, M., Baughcum, E., \& Specker, L. (2000). The relationship of childhood adiposity to parent body mass index and eating behavior. Obesity Research, 8, 234-240.

Whitaker, R.C., Wright, J.A., Pepe, M.S., Seidel, K.D., \& Dietz, W.H. (1997). Predicting obesity in young adulthood from childhood and parental obesity. New England Journal of Medicine, 337, 869-873.

Wisemandle, W., Maynard, M., Guo, S., \& Siervogel M. (2000). Childhood weight, stature, and body mass index among never overweight, early-onset overweight, and late-onset overweight groups. Pediatrics, 106, 14-27.

World Health Organization (1968). Nutritional anemia: Report of a WHO scientific group. (Technical Report Series No. 405). Geneva, Switzerland: WHO.

World Health Organization (1988). Measuring obesity: Classification and description of anthropometric data. (Report on a WHO consultation on the epidemiology of obesity). Copenhagen, Denmark: WHO Regional Office for Europe.

Yip, R. (1989). The changing characteristics of childhood iron nutritional status in the United States. In: L.J.Filers, Jr.(Ed.), Dietary iron: Birth to two years (pp: 37-61). New York, NY: Raven Press.

Zuguo, M., Kelley, S., Laurence, M., Grummer, S., David, S., Yip, F., \& Frederick, L. (1998). Increasing prevalence of overweight among US low-income preschool children: The Centers for Disease Control and Prevention Pediatric Nutrition Surveillance, 1983 to 1995. Pediatrics, 101, 12. 
APPENDICES 

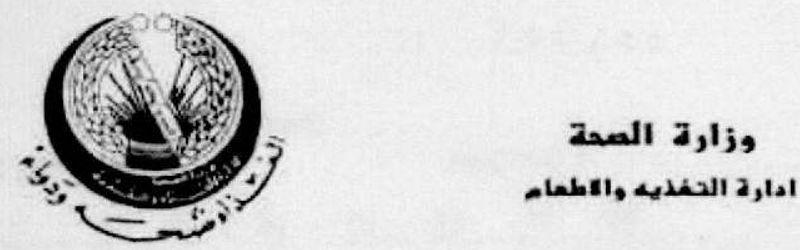

Dr. Fatma G. Huffman

101312001

Professor

Department of Dietetics \& Nutrition

College of Health Science

University Rark, Miami,

Florista 33199

U. S A

Fax: (305) 348-1996

\section{Ref: Data related to Kuwaiti mothers and their children}

Dear Di Huffman,

Received your letter dated January 31, 2001. We have sent datu felated to Kuwaiti mothers and their children to Mr. Al-Haifi for his MS thesis Hope it will be of help to conplete his thesis.

With best regards

Yours Sincerely.

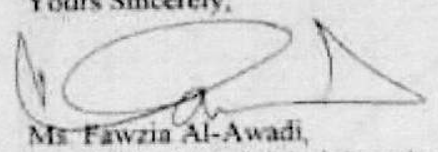

Ms Favzia Al-Awadi,

Head of Food and Administration Departuent

Ministry of Health

Kuwain

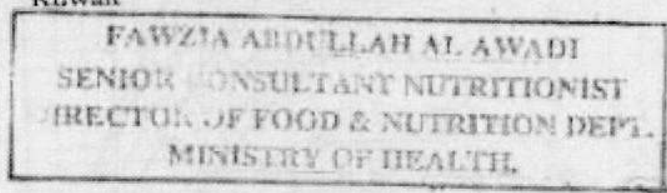

P.O. HoT 4QTE SAFAT

STATE OP KUWATT 13041

FAX: 4813905 


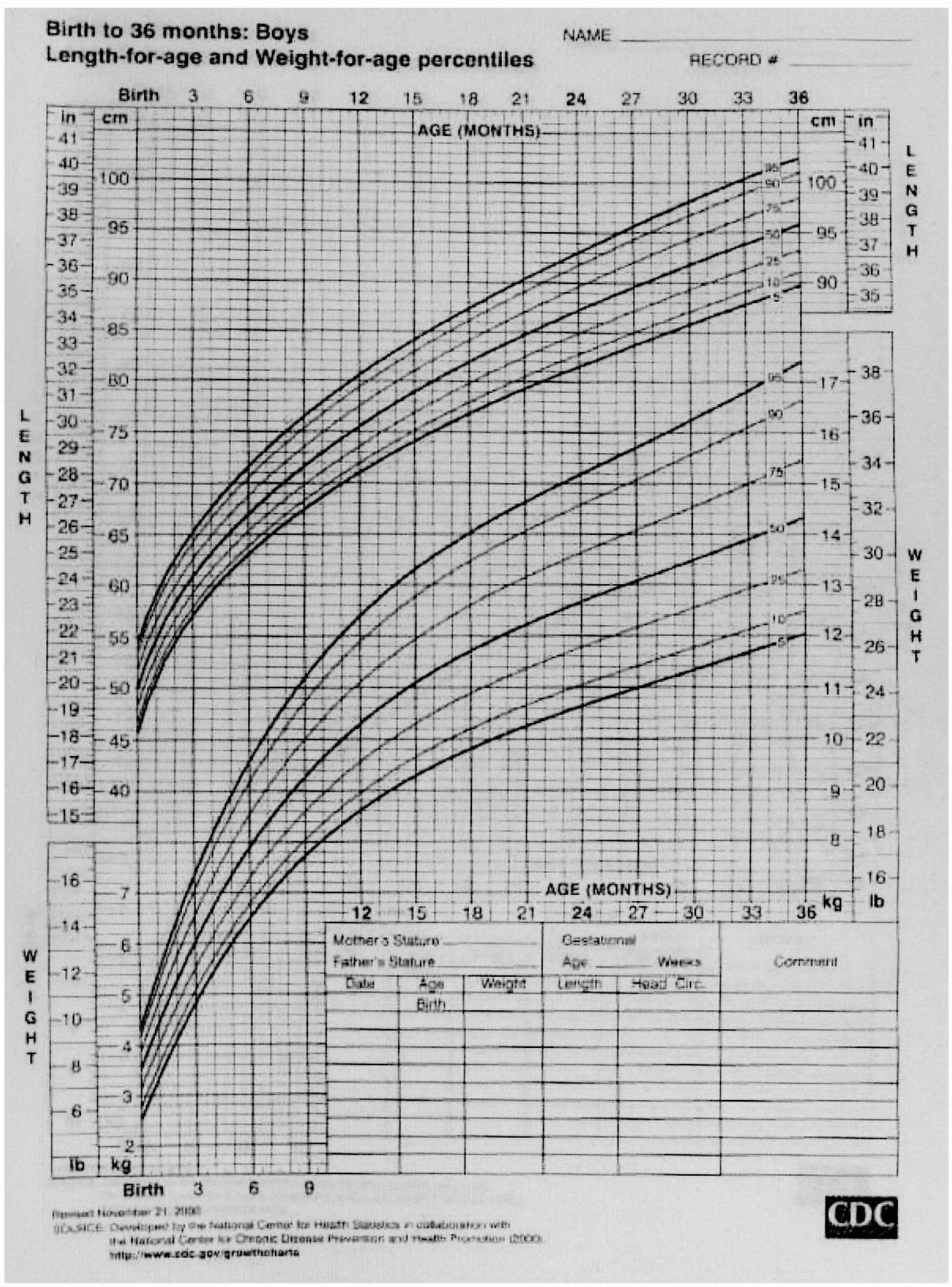


Birth to 36 months: Girls

Length-for-age and Weight-for-age percentiles

NAME

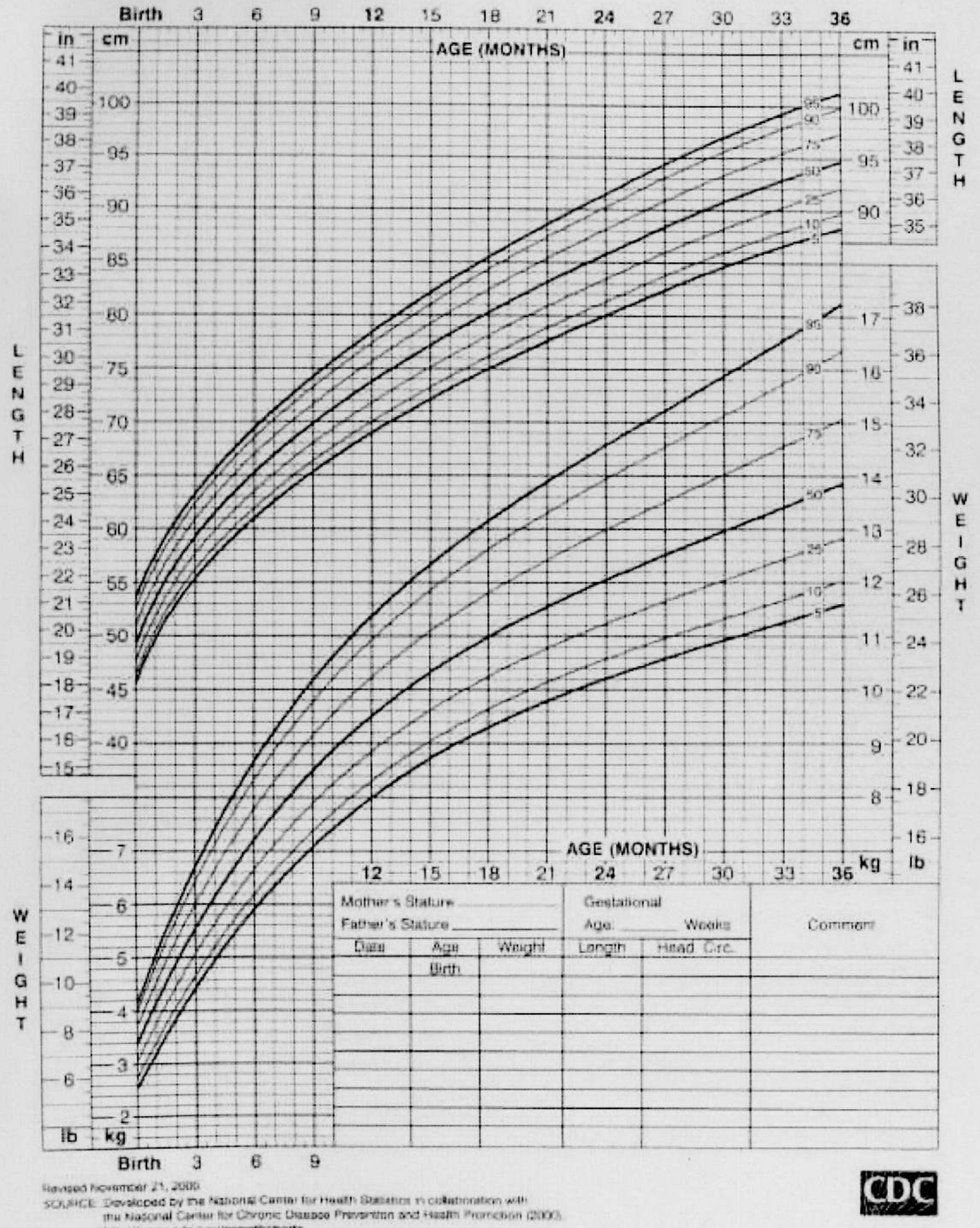

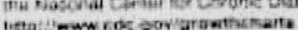

